\title{
The Role of Narcissistic Hypocrisy in the Development of Accounting Estimates*
}

\author{
Matthew J. Hayes, Assistant Professor ${ }^{\dagger}$ \\ College of Business \\ University of Michigan - Dearborn \\ Philip Reckers, Professor \\ School of Accoutancy, WP Carey School of Business \\ Arizona State University
}

\begin{abstract}
* Accepted by Susan Krische. This paper is based on Professor Hayes' dissertation completed at Arizona State University. He would like to thank his dissertation committee: Phil Reckers (Chair), Jordan Lowe, and Eldar Maksymov for their guidance, and also acknowledge Mike Mowchan, Artur Hugon, Michal Matějka, Stacey Whitecotton, Lucile Faurel, Phil Drake, Don Lange, and Berthold Herrendorf for their assistance and support, as well as workshop participants at Arizona State, Ivey Business School, and the University of Michigan - Dearborn, and financial support from the University of Michigan - Dearborn. The authors would also like to thank Susan Krische and two anonymous reviewers for their helpful comments and suggestions. Data available upon request.

† Corresponding author: 19000 Hubbard Drive, Dearborn, MI 48126, 313-593-5247, hayesmj@umich.edu
\end{abstract}

This is the author manuscript accepted for publication and has undergone full peer review but has not been through the copyediting, typesetting, pagination and proofreading process, which may lead to differences between this version and the Version of Record. Please cite this article as doi: 10.1111/1911-3846.12552

This article is protected by copyright. All rights reserved. 
The Role of Narcissistic Hypocrisy in the Development of Accounting Estimates

\begin{abstract}
In an experiment including experienced managers, we investigate how supervisor and subordinate narcissism influence a supervisor's review of a subordinate's accounting estimate. While narcissistic supervisors express greater liking for narcissistic subordinates (narcissistic tolerance), they nonetheless reject and revise the accounting estimates of narcissistic subordinates to a greater extent than they reject estimates of non-narcissistic subordinates (narcissistic hypocrisy), even when doing so inhibits the supervisor's ability to reach a profit target. Our findings contribute to extant research in accounting and psychology. We demonstrate that narcissistic hypocrisy extends beyond the evaluation of others, and alters narcissists' willingness to rely on other narcissists in a meaningful financial reporting decision. We also find that narcissistic hypocrisy is robust across age, gender and supervisory experience.
\end{abstract}

Keywords: narcissism, narcissistic tolerance, narcissistic hypocrisy, accounting estimates

This article is protected by copyright. All rights reserved. 


\section{The Role of Narcissistic Hypocrisy in the Development of Accounting Estimates}

\section{Introduction}

The integrity of accounting information depends on a system of effective quality controls advanced by a program of checks and balances (COSO 2013). For example, an accounting estimate initiated by a subordinate staff member must be reviewed (i.e., approved or revised) by a supervisor before it is recorded. The review serves to detect and correct potential material misstatements. However, the effectiveness of the review depends on the supervisor's ability to maintain objectivity (COSO 2009). We investigate how both supervisor and subordinate narcissism will influence this review and, specifically, how supervisor reliance on subordinate work will be affected. ${ }^{1}$ Many researchers have previously examined the organizational effects of narcissistic executives (e.g., Olsen, Dworkis, and Young 2013; Olsen and Stekelberg 2015; Ham, et al. 2017; Judd, Olsen, and Stekelberg 2017), including the actions of subordinates in response to executive narcissism (Braun et al. 2018). We believe we are among the first to examine how subordinate narcissism influences supervisors, as well as the interaction between supervisor and subordinate narcissism.

There is ample evidence to suggest narcissism is on the rise in the U.S. population (Twenge et al 2008; Twenge and Campbell 2008; Twenge and Foster 2010), and with it, researchers' interest in the manifold effects of narcissism (Young et al. 2016). Much of this

\footnotetext{
${ }^{1}$ We examine grandiose narcissism, characterized by grandiosity, entitlement, extroversion, attention-seeking, authoritativeness, and exploitativeness (Miller et al. 2011). Unless otherwise specified, references to "narcissism” in the manuscript are to grandiose narcissism.
} 
research has focused on the negative impact of narcissism (Johnson et al. 2012; Olsen et al. 2013; Paulhus 2014; Olsen and Stekelberg 2015; Judd et al. 2016; Ham et al. 2017). Typically, these studies find executive narcissism is associated with untoward executive behavior, such as greater earnings management (Olsen et al. 2013; and Ham et al. 2017).

There is also a growing literature on how narcissistic executives influence individuals within an organization. For example, Braun et al. (2018) find that subordinates have negative emotional reactions to leader narcissism, resulting in increased counterproductive work behavior. However, there is a paucity of studies examining supervisors’ reactions to subordinate narcissism, and the interaction of supervisor and subordinate narcissism. Wisse, Barelds, and Rietzschel (2015) provide some evidence on this matter. They find that narcissistic subordinates are rated as more innovative by their supervisors. However, these ratings are moderated by supervisor narcissism; narcissistic supervisors rate narcissistic subordinates as less innovative. We extend this line of research by examining supervisors' use of subordinate input, rather than merely supervisors’ perceptions (i.e., evaluations) of subordinates. Our approach allows us to examine the extent to which managers' impressions affect their actions and identify a tangible outcome of the interaction between narcissistic personalities that has implications for reporting quality.

We test whether subordinate narcissism will influence a supervisor's reliance on input from that subordinate. We expect reliance will depend on the supervisor's own narcissism. If this is the case, varying degrees of supervisor and subordinate narcissism may adversely affect 
reporting quality. This may especially be the case with respect to accounting estimates. Estimates are subjective by their very nature, and negative or positive framing of subordinate input may impair information integrity.

Our hypotheses leverage prior studies advancing the co-existing theories of narcissistic tolerance (i.e., narcissists are more accepting of other narcissists’ traits) and narcissistic hypocrisy (i.e., despite this professed acceptance, narcissists do not demonstrate tolerance of narcissistic actions directed toward them). Hart and Adams (2014) find that narcissists (relative to non-narcissists) rate others exhibiting narcissistic traits more positively. They call this conditional liking narcissistic tolerance, and it appears to be driven by perceived similarity to self (Burton et al. 2017). Several studies report findings consistent with narcissistic tolerance (e.g., Wallace et al. 2015; Burton et al. 2017). However, Adams, Hart, and Burton (2015) provide evidence of narcissistic hypocrisy. They find that, while narcissists appear to like the idea of a narcissistic other, they are not receptive of others acting narcissistically.

One explanation for narcissistic hypocrisy is that narcissists are protective of their grandiose self-images and are likely to aggress against those who threaten their egos (Bushman and Baumeister 1998; Jones and Paulhus 2010; Wisse, et al. 2015). This is highly relevant in a competitive workplace, where narcissists might be especially sensitive to being outshone. Even though narcissistic supervisors may appear to have a "soft spot" for narcissistic subordinates, they may be less supportive of other narcissists that they view as potential threats. 
Using experimental methods, we examine the influence of supervisor and subordinate narcissism on a supervisor's review of a subordinate's proposed inventory write-down for estimated obsolescence. Participants role-play a division manager, who is responsible for reviewing a proposed inventory write-down. The discretionary nature and inherent ambiguity of an inventory valuation allow for a range of acceptable estimates and greater latitude in judgment. In all cases, the subordinate provides an income-favorable estimate for the write-down (i.e., a smaller write-down), which allows the division to meet a profit target. We manipulate the description of the subordinate providing the estimate, as exhibiting high or low narcissism, holding knowledge, skill, and ability constant. We measure participant narcissism using the Grandiose Narcissism Scale (Foster et al. 2015).

Our findings provide evidence of both narcissistic tolerance and narcissistic hypocrisy. Compared to supervisors low in narcissism, supervisors high in narcissism rate a narcissistic subordinate as more likable (consistent with narcissistic tolerance); however, this tolerance does not extend to acceptance of the subordinate's recommendation. We find a significant interaction between supervisor and subordinate narcissism, where narcissistic supervisors make larger, income-decreasing adjustments to the proposed estimates of narcissistic subordinates (consistent with narcissistic hypocrisy). Our results are robust to controlling for supervisor age, gender and supervisory experience.

We corroborate and extend prior research by examining not only how narcissistic supervisors perceive narcissistic subordinates, but also how subordinate narcissism influences 
supervisors' reliance on their work. We confirm that narcissistic supervisors rate narcissistic subordinates more favorably (exhibiting narcissistic tolerance). We extend recent research by documenting an interactive effect of supervisor and subordinate narcissism, resulting in narcissistic hypocrisy that goes beyond personal evaluations. Narcissistic supervisors make greater revisions to narcissistic subordinates' recommendations, even when those revisions impede the achievement of an earnings goal.

Our research contributes to the accounting, management, and psychology literatures. Our findings emphasize the collaborative nature of financial reporting and highlight the importance of interpersonal interactions in accounting decisions. While prior accounting studies have focused on the relationship between executive personality characteristics (including narcissism) and reporting quality (e.g., Murphy 2012; Schrand and Zechman 2012; Ahmed and Duellman 2013; Olsen et al. 2013; Jia, Lent, and Zeng 2014), our work suggests the study of narcissism should not be restricted to the traits of top-level managers and top-down effects. We demonstrate that subordinate narcissism has a bottom-up effect and that both supervisor and subordinate narcissism have a significant influence on supervisors' reliance on the work of subordinates.

We also contribute to the psychology and management literatures by demonstrating the effect of narcissistic hypocrisy on a business decision. Prior research in this area is concentrated on how narcissists evaluate other narcissists. We provide evidence that the favorable attitudes of narcissistic supervisors towards narcissistic subordinates does not spill over to greater reliance on their work product. To the contrary, our evidence suggests narcissistic hypocrisy results in 
narcissistic supervisors making significant revisions to input provided by narcissistic subordinates.

The remainder of the paper proceeds as follows: Section II discusses the development of our hypotheses, Section III explains our methodology and experimental design, Section IV reports the results of the experiment, and Section $\mathrm{V}$ provides a discussion of the results and conclusions of our research.

\section{Background and Hypotheses}

\section{Grandiose narcissism}

Narcissism is a complex construct. Researchers generally agree there are two broad categories of narcissism, grandiose and vulnerable narcissism (Dickinson and Pincus 2003; Miller et al. 2011). Grandiose narcissism, the focus of our paper, is the type more commonly encountered in daily life. Also called overt narcissism, grandiose narcissism is what many would consider as the stereotypical image of narcissism: arrogance, a sense of entitlement, and acclaimseeking and exploitative behavior, with a propensity for self-enhancement. On the other hand, vulnerable narcissism is also known as covert, or closet narcissism. While vulnerable narcissists also have a sense of entitlement and high expectations, they hide under less flashy personalities, even coming across as shy or modest (see Johnson, Kidwell, Lowe and Reckers, 2019).

The Narcissistic Personality Inventory (NPI), the most widely used measure of subclinical narcissism, is a measure of grandiose narcissism (Miller et al. 2011, Foster et al. 2015). Raskin and Terry (1998) originally proposed seven underlying factors of grandiose 
narcissism: 1) authority, 2) self-sufficiency, 3) vanity, 4) superiority, 5) exhibitionism, 6) entitlement, and 7) exploitativeness. There is strong consensus that each of these factors relates to the construct of grandiose narcissism. While the NPI functions acceptably as a global measure of grandiose narcissism, researchers have had problems using it to reliably measure the seven subcomponents (Corry et al. 2008; Ackerman et al. 2011). To address this issue, Foster et al. 2015 created the thirty-three item Grandiose Narcissism Scale (GNS), specifically designed to provide an improved overall measure of grandiose narcissism while also measuring each of the seven subcomponents more reliably. We use the more recent GNS measure in our research.

\section{Narcissism in the workplace}

Narcissists are often perceived favorably because of characteristics such as charisma, personal charm, extroversion, and confidence (Grijalva et al. 2015a). Many successful CEOs, athletes, musicians, and entertainers exhibit characteristics associated with narcissism, such as progressive, fashion forward ideas, confidence, and personal charisma (Maccoby 2000). However, researchers have also linked narcissism to negative and destructive behaviors. These negative behaviors include an abusive management style, excessive risk taking, resisting advice, and lapses in professional or ethical judgment (Rosenthal and Pittinsky 2006). Narcissism among corporate executives has been associated with greater earnings management (Olsen et al. 2013, Ham et al. 2017), and aggressive tax avoidance (Olsen and Stekelberg 2015). Studies have also demonstrated that external auditors respond negatively to narcissism in client executives by

This article is protected by copyright. All rights reserved. 
increasing assessments of fraud risk (Johnson et al. 2012), and audit fees (Judd et al. 2017), implying that narcissism is not universally perceived positively.

While there is a significant literature on narcissistic leaders, there is less research on the effects of narcissism in subordinates. Relevant to our work, Blair et al. (2008) measured narcissism in a sample of executive MBA students, and then had each of the students' immediate work-place supervisors and subordinates complete performance appraisals. They found narcissism was correlated with lower ratings of integrity and interpersonal skills from supervisors but was uncorrelated to ratings on the same dimensions from subordinates. Similarly, Judge, LePine, and Rich (2006) found that subordinate narcissism was positively related to supervisor ratings of employee workplace deviance (i.e., counterproductive behaviors, such as not following instructions). These studies suggest supervisors may view narcissistic subordinates more negatively, but neither study measured both supervisor and subordinate narcissism.

We found only one study that examined the interactive effect of supervisor and subordinate narcissism. Wisse et al. (2015) examined how narcissistic supervisors rated the innovativeness of narcissistic subordinates. They found that supervisors rated more narcissistic subordinates as more innovative, but ratings were moderated by supervisor narcissism. Narcissistic supervisors rated narcissistic subordinates as less innovative. We aim to expand the research on narcissistic supervisors and subordinates by examining not only narcissistic supervisor perceptions of narcissistic subordinates, but also the degree to which narcissistic supervisors rely (or do not rely) on the work of narcissistic subordinates. Our research will shed 
light on how the interaction of narcissistic personalities in supervisors and subordinates can affect the financial reporting process.

\section{Narcissistic Tolerance}

There are several studies in the broader social psychology literature examining narcissists’ reactions toward other narcissists. Hart and Adams (2014) is an example of one study demonstrating narcissists' favorable response to other narcissists. They measured narcissism in a large pool of undergraduate students, and subsequently had the students rate the likability of a series of hypothetical people possessing one of eleven different traits associated with narcissism (e.g., aggressive, arrogant, flashy), as well as the extent to which the students' believed they themselves possessed those same traits. They found that narcissistic individuals rated others possessing narcissistic traits more positively. Further, they found that students' liking of narcissistic others positively correlated with how strongly the students believed they possessed narcissistic traits, and this measure of self-possession of narcissistic traits mediated the relationship between student narcissism and ratings of other narcissists. They conclude that narcissistic tolerance appears to be driven by perceived similarity.

Wallace et al. (2015) and Burton et al. (2017) replicated the findings of Hart and Adams (2014) under different conditions. Wallace et al. (2015) created profiles of narcissistic and nonnarcissistic individuals based on NPI items (e.g., “I am an extraordinary person”), and asked participants to rate the extent to which they held a positive view of that person. Overall, participants rated the non-narcissistic profile more favorably. However, when rating the 
narcissistic profile, high narcissism participants gave higher ratings than low narcissism participants. Burton et al. (2017) created video clips of actors providing narcissistic and nonnarcissistic responses to questions and found similar results. Participants reported higher likability ratings for the non-narcissistic response, but when rating the narcissistic response, participants higher in narcissism provided higher likability ratings than participants lower in narcissism. Based on these findings, we predict that narcissistic supervisors will exhibit narcissistic tolerance when evaluating the likability of narcissistic subordinates.

HYPOTHESIS 1: Compared to low narcissism supervisors, supervisors high in narcissism will rate narcissistic subordinates as more likable.

\section{Narcissistic hypocrisy}

A positive view of someone in one aspect of social interaction can spill over into other, unrelated aspects of a relationship (i.e., the "halo effect"). Thus, one might expect that narcissistic supervisors exhibiting a favorable likability for narcissistic subordinates would take a similar favorable attitude toward their work product. However, an alternative possibility is that narcissistic superiors view narcissistic subordinates as ego threats and seek to aggress against them. An ego threat can be anything that threatens one’s positive self-image (Leary, et al. 2009). Narcissists' strong desire to maintain their own ego (that is, their grandiose, superior self-image) often leads to aggressive reactions towards perceived ego threats (Bushman and Baumeister 1998; Bogart, Bentosch, and Pavlovic 2004; Jones and Paulhus 2010; Back et al. 2013; Wisse et al. 2015).

This article is protected by copyright. All rights reserved. 
Baumeister, Smart, and Boden (1996) proposed that narcissists would be particularly prone to aggressive responses to ego threat because of their inflated self-perceptions and their preoccupation with convincing others of their superiority. Bushman and Baumeister (1998) empirically tested this conjecture by examining how narcissists responded to ego threats (operationalized via an insult). They found that narcissism was associated with more aggressive behavior toward the source of an ego threat, and that perceived threat mediated the relationship between narcissism and aggressive behavior. Bogart et al. (2004) examined narcissists' responses to a more subtle, indirect form of ego threat: comparing themselves to others. They observed that narcissists were more inclined to compare themselves to others, and merely comparing themselves to someone they view as an ego threat caused narcissists to experience feelings of hostility. We could not find research explicitly examining narcissists' comparison to other narcissists. However, Adams et al. (2015) found that narcissistic tolerance dissipated when narcissists were confronted with narcissistic behaviors. They termed this narcissistic hypocrisy, and it suggests that narcissists view other narcissists as ego threats.

Wisse et al. (2015) documented a similar effect in a work context; they measured narcissism in 306 supervisor-subordinate pairs of Dutch service workers and had each supervisor rate the subordinates' innovativeness. After finding that narcissistic supervisors rated narcissistic subordinates as less innovative, the authors speculated that this interaction may have been caused by narcissistic supervisors feeling threatened by a subordinate "stealing their thunder.” From 
these studies, we infer that narcissistic hypocrisy is likely to manifest if a narcissistic subordinate is perceived as a threat to a narcissistic supervisor's ego.

These prior findings appear highly relevant to a work environment in which a supervisor must decide whether to rely or not on a subordinate's work. We specifically selected a situation where a supervisor must choose to accept, or adjust, a subordinate’s proposed inventory adjustment. By doing so, we believe we focus on common financial reporting matters: reliance on subordinates' work and management of earnings to achieve an earnings target. In our setting, a conservative accounting estimate results in missing the earnings target, but a more aggressive (i.e., income favorable) estimate results in meeting or exceeding the target. On the one hand, if a subordinate suggests a more aggressive estimate, a supervisor may be inclined to agree in order to meet the earnings target. However, narcissistic hypocrisy suggests that narcissistic supervisors may view the narcissistic subordinate as an ego threat. As a response to this ego threat, narcissistic supervisors may temper their subordinates’ suggestions (i.e., choose to sacrifice the earnings goal in order to secure reputational superiority relative to the narcissistic subordinate). HYPOTHESIS 2: Supervisors who exhibit greater narcissism will make larger negative adjustments to aggressive accounting estimates proposed by subordinates who also exhibit greater narcissism.

\section{Method}

\section{Design and Participants}

This article is protected by copyright. All rights reserved. 
We tested our hypotheses in a between-subjects experiment. ${ }^{2}$ Participants role-played as a division manager who was responsible for reviewing and approving an inventory obsolescence estimate advanced by a subordinate. We manipulated the narcissistic attributes of the subordinate who generated the estimate. Participant narcissism was a measured independent variable.

We utilized TurkPrime Panels to recruit participants. This service recruits participants from various online platforms (e.g., SurveyMonkey and Qualtrics). We paid a fee to TurkPrime, which pays the other platforms for access to their "panels" of participants. Studies conducted in this fashion draw participants from several different services. The amount and form of participant compensation varies by service. Frequently used compensation forms include cash, reward points, gift cards, and charitable donations. Neither we nor TurkPrime were able to control or collect participant compensation information, so we cannot determine the average compensation for completing our study. Our cost was $\$ 8$ per respondent.

We required participants to reside in the United States, be at least 18 years of age, and hold an MBA degree from a U.S. university. Four hundred and seventeen participants attempted our instrument, 110 participants were disqualified for not having an MBA degree, six participants had to be discarded due to an instrument malfunction (specifically, they were not introduced to the narcissism manipulation), and an additional 47 participants were discarded for

\footnotetext{
${ }^{2}$ IRB approval was granted for the use of human subjects.
} 
failing the manipulation check regarding their perceptions of subordinate narcissism (as described below). We conducted our analyses with the remaining 254 participants. ${ }^{3}$

Prior research has shown that people can effectively identify narcissism in others (e.g., Buffardi and Campbell 2008; Friedman, Oltmanns, and Turkheimer 2008; Vazire, Naumann, Rentfrow, and Gosling 2011). After reading a description of a subordinate employee (manipulated to exhibit characteristics consistent with high/low narcissism), participants were asked to rate their agreement with the statement, "Casey Jones (the subordinate) is narcissistic" using a seven-point Likert scale (1 - strongly disagree, 7 - strongly agree). ${ }^{4}$

The 254 participants retained in our analyses took an average of 10.5 minutes to complete the instrument. The average participant was 47 years-old, the sample was 52\% male, and 80 percent of participants reported having managerial experience, with an average of 13.7 years (SD = 11.7) of experience. Libby, Bloomfield, and Nelson (2002) recommend matching participants to the goals of the study. We are investigating how mid-level managers make reporting decisions; as such, we feel our sample is an adequate proxy.

\footnotetext{
${ }^{3}$ Using all 301 participants in our primary tests does not alter the statistical conclusions regarding Hypothesis 1, but Hypothesis 2 is no longer supported. However, if we use participants' perceptions of subordinate narcissism (based on manipulation check responses) rather than the assigned manipulation condition, statistical inferences of our primary tests for both hypotheses are unchanged, with both Hypotheses 1 and 2 supported.

${ }^{4}$ We excluded forty-seven participants for misidentifying high/low subordinate narcissism. These participants did not have statistical differences in age, gender, or experience from the 254 remaining participants. They did score significantly higher on the narcissism measure $(M=155.77, S D=33.22)$ than those retained $(M=142.39, S D=$ 26.49), $\mathrm{t}(299)=3.047, \mathrm{p}=0.003$. Performance on two attention check questions suggests misidentification was caused by inattentiveness, rather than misinterpretation of the subordinate description. The first question asked participants how the inventory write-down will impact current year profit, the second asked them to recall why the product line must be written down. Of the 254 (47) participants who passed (failed) the manipulation check, 82\% (68\%) answered the first question correctly, 91\% (75\%) answered the second question correctly, and $80 \%$ (66\%) answered both questions correctly. All pass rates are statistically different at $\mathrm{p}<0.05$.
} 


\section{Procedure}

Participants first completed screening questions to verify their education. Next, they completed the 33-item Grandiose Narcissism Scale (GNS) from Foster et al. (2015). We chose this scale over the more well-known NPI (Raskin and Terry 1988) because of inconsistencies in the factor structure of the NPI, as well as criticisms of its forced-choice format (Miller et al. 2017). The GNS reproduces the original NPI seven-factor structure (i.e., authority, selfsufficiency, superiority, vanity, exhibitionism, entitlement, and exploitativeness), and can be used as an overall measure of narcissism. After the GNS, standard demographic information was recorded (including age, gender, and managerial experience).

Participants then read a scenario where they assumed the role of a division manager tasked with reviewing a proposed inventory write-down and deciding on the final amount of the write-down. We provided participants with a probable range for the value of the inventory (\$500,000 - \$900,000) and a “most likely” value of $\$ 700,000$. We also gave participants a division profit target and demonstrated how various write-down amounts would affect division profit. If the inventory was written down below $\$ 800,000$, the division would not meet the profit target, and the "most likely" inventory value resulted in missing the profit target.

GAAP requires inventory be recorded at the lower of 1) the cost of inventory or 2) the net realizable value, which is the estimated selling price less any "reasonably predictable” costs to complete and sell the inventory (ASC 330). The scenario involved slow moving inventory from a new product line that was not performing as well as expected. This created uncertainty 
surrounding the selling price, and how steeply the inventory would need to be discounted, which gave participants leeway to deviate from the "most likely" amount. We instructed participants that meeting or exceeding the profit target was an important part of their performance evaluation. However, we did not provide actual economic incentives to choose a higher inventory valuation or record a smaller write-down. Experimental compensation was unrelated to the inventory value choice.

After the scenario, we gave participants a description of their subordinate employee (that is, the assistant controller), and the subordinate's recommendation for the inventory write-down. In all cases the subordinate recommends an aggressive, high-value, inventory estimate (i.e., a small write-down), valuing the inventory at $\$ 850,000$, which allows the division to meet the earnings target. After reviewing the subordinate estimate, participants chose the amount they would approve for the estimate. Following the main experimental materials, participants answered several follow-up questions regarding their impressions of the subordinate.

\section{Independent Variables}

We manipulated the subordinate description at two levels: high and low narcissism. Prior studies manipulating narcissism employ descriptions of fictitious individuals built from characteristics frequently used to describe high or low narcissists (e.g., Hart and Adams 2014; Adams et al. 2015) or directly from narcissism measures (e.g., Wallace et al. 2015). High narcissism characteristics used by prior studies include aggressive, rude, arrogant, bossy, selfish, 
and flashy. Low narcissism characteristics include sensitive, gentle, timid, modest, and cooperative.

Narcissism is a multi-faceted construct, as such, we designed our manipulations using the “360 degree” approach recommended by Lipe (2018). We utilized multiple cues representing different dimensions of the construct of interest to create manipulations that are more representative of an individual high or low in narcissism. We based our manipulations on the seven subcomponents of the GNS: 1) authority, 2) self-sufficiency, 3) superiority, 4) vanity, 5) exhibitionism, 6) entitlement, and 7) exploitativeness.

In the high narcissism condition, the subordinate is described as a person who puts a lot of emphasis on physical appearance (high vanity), who loves compliments (high exhibitionism), who expects to get what he wants (high entitlement), who is willing to leverage situations to create an advantage (high exploitativeness), who believes he is better than others (high superiority), who enjoys being an authority (high authority), and who does not like to delegate (high self-sufficient). We also stated that co-workers describe this individual as a narcissist.

In the low narcissism condition, the subordinate is described as a person who is not hung up on physical appearance (low vanity), who does not like to show off and is embarrassed by compliments (low exhibitionism), who hopes to get what he wants (low entitlement), who is reluctant to leverage situations (low exploitativeness), who recognizes his weaknesses and others' strengths (low superiority), who is willing to cede to authority (low authority), and who is willing to delegate (low self-sufficiency). We stated that co-workers describe this individual as 
modest. To try to reduce divergent impressions of non-narcissistic characteristics, the high and low narcissism subordinate each had the same background information. We described each as educated, ambitious, hardworking, personable, and funny. The exact wording of these conditions can be seen in our survey, provided in the online Appendix. ${ }^{5}$

Participant narcissism is the second independent variable of interest and was measured with the GNS. We recorded participant responses to the 33 GNS items on a seven-point Likert scale $(1=$ strongly disagree, 7 = strongly agree). All GNS items are phrased such that stronger agreement (higher values) indicate more narcissistic responses. The total GNS score is calculated by summing the individual items. The mean GNS score was 142.39 (SD = 26.49, $\mathrm{n}=254)$, and the scale exhibited strong reliability $(\alpha=.93)$. The mean is slightly higher than in samples reported in Foster et al. (2015). ${ }^{6}$ We believe this may be due in part to two factors. First, they sampled a more heterogeneous population of college students, whereas we focus on business professionals. Second, their samples contained a higher percentage of females (61\% and 75\% in Foster et al. 2015, compared to $48 \%$ in our sample). Prior research suggests that females are less narcissistic than males (Grijalva et al. 2015b).

\section{Dependent Variables}

\footnotetext{
${ }^{5}$ Please see supporting information, “Online Appendix: Subordinate Narcissism Manipulations” as an addition to the online article.

${ }^{6}$ Foster et al. (2015) reported means of $114.66(\mathrm{SD}=22.32, \mathrm{n}=980)$ and $110.71(\mathrm{SD}=21.34, \mathrm{n}=262)$. However, they recorded participant responses on a six-point scale, whereas we used a seven-point scale. To facilitate comparison, we converted total scores to percentages, based on the maximum possible score for each scale. Our average score was $61.6 \%$ of the maximum, the Foster et al. (2015) averages were $57.9 \%$ and $55.6 \%$ of the maximum, respectively.
} 
To investigate H1, we asked participants to rate their agreement with the statement, “Casey Jones (the subordinate) is a likable person”, using a seven-point Likert scale (1 - strongly disagree, 7 - strongly agree). To investigate H2, we analyzed participant choices for the inventory write-down. We gave participants the following prompt, “As division manager, you are responsible for approving the inventory value amount. What amount would you record as the value of the inventory?” Participants responded by selecting an amount from a drop-down list of values between $\$ 500,000$ - $\$ 900,000$, in increments of $\$ 50,000$.

\section{Results}

\section{Descriptive Statistics}

Descriptive statistics and Spearman correlations are provided in Table 1. The sample was 52\% male. Of the 254 participants, 129 (125) received the low (high) subordinate narcissism manipulation. Consistent with prior literature, age has a negative correlation with participant narcissism $(G N S){ }^{7}$ The correlation between gender and narcissism is not significant but is directionally consistent with prior studies that find females to be less narcissistic.

\section{[INSERT TABLE 1]}

Since subordinate narcissism (SubNarc) was manipulated, and participants were randomly assigned to receive either a high or low narcissism subordinate description, we did not

\footnotetext{
${ }^{7}$ Foster et al. (2003) utilizes a cross-sectional design, with data collected at a single point in time, to demonstrate that older people report lower narcissism scores. Due to the relatively recent development of narcissism measures, to our knowledge, there has not been a longitudinal study of narcissism to determine how individual narcissism changes over time. The observed negative relationship cannot be clearly attributed to either a) a decline in narcissism as individuals get older or b) an increase in narcissism in younger age groups (or some combination of the two).
} 
expect, or find, SubNarc to be correlated with participant narcissism (GNS). We do observe correlations consistent with our theory. Subnarc has a negative correlation with participants' inventory estimates and likeability ratings, and a positive correlation with participants’ career threat perceptions. Participant inventory values have a positive correlation with ratings of subordinate likeability, but a negative correlation with perceptions of career threat.

Our main statistical tests, reported below, are robust to controlling for both age and gender. There are also no statistically significant interactions between age, or gender, and subordinate narcissism. Older and younger people responded to subordinate narcissism in the same manner, as did males and females.

\section{Hypotheses Tests}

To test H1, we analyze participant responses regarding the subordinate likability using multiple regression. We estimate the following regression equation:

$$
\text { (1) } \text { Likable }=\beta_{0}+\beta_{1} \text { SubNarc }+\beta_{2} G N S+\beta_{3} \text { SubNarc } x \text { GNS }
$$

[INSERT TABLE 2]

SubNarc is a dummy variable equal to $1(0)$ if the participant was given the high (low) narcissism subordinate description. GNS is the participant's narcissism as measured by their GNS score. We mean centered the GNS scores to reduce multicollinearity and improve interpretability of the model coefficients (West, Aiken, and Krull 1996). The results of the regression are reported in Table 2. We find a significant main effect for SubNarc; participants rated the narcissistic subordinate significantly less likable $\left(\beta_{1}=-2.33, \mathrm{p}<0.001\right)$. The main 
effect for GNS is not significant; however, we do see a significant interaction between SubNarc and GNS $\left(\beta_{3}=0.012, \mathrm{p}<0.039\right)$. The positive sign indicates that narcissistic participants rated the narcissistic subordinate as more likable, which is consistent with narcissistic tolerance theory. ${ }^{8}$

\section{[INSERT FIGURE 1]}

Figure 1 depicts estimates produced from the regression equation for both the low and high subordinate narcissism conditions. The Y-axis represents the estimated participant likability rating for the subordinate. The $\mathrm{X}$-axis varies participant narcissism for the range of GNS scores that are $+/$ - one standard deviation from the mean GNS score $(\mathrm{M}=142.39$, SD = 26.49), as recommended by West et al. (1996). The regression estimates show consistently high likability ratings for the low narcissism subordinate, regardless of participant narcissism. However, likability of the high narcissism subordinate depends on participant narcissism. Narcissistic participants find the high narcissism subordinate to be more likable. These results support H1.

To test H2, we analyze participant choices for the inventory value. A higher inventory value results in a lower write-down, and inventory values of at least $\$ 800,000$ allow the division to meet the profit target. We estimate the following regression equation:

(2) Inventory $=\beta_{0}+\beta_{1}$ SubNarc $+\beta_{2} G N S+\beta_{3} \operatorname{SubNarc} x$ GNS

[INSERT TABLE 3]

\footnotetext{
${ }^{8}$ We note the relatively high $\mathrm{R}^{2}$ reported in Table $2\left(\mathrm{R}^{2}=50 \%\right)$; this is attributable to the strong correlation between subordinate narcissism and likability $(\mathrm{r}=-0.692, \mathrm{p}<0.01)$.
} 
All independent variables are the same as Equation 1. The results of the regression are reported in Table 3. We find a significant main effect for $\operatorname{SubNarc}\left(\beta_{1}=-40.710, \mathrm{p}<0.001\right)$, with participants making lower estimates when the subordinate is narcissistic. We also find a significant main effect for GNS $\left(\beta_{2}=0.660, \mathrm{p}=0.042\right)$ with narcissistic participants making higher estimates. However, we also find a significant interaction between SubNarc and GNS ( $\beta_{3}$ $=-0.923, \mathrm{p}=0.030$ ). Consistent with narcissistic hypocrisy, narcissistic participants make lower estimates when the subordinate is also narcissistic.

\section{[INSERT FIGURE 2]}

Figure 2 depicts estimates produced from the regression equation for both the low and high subordinate narcissism conditions. The Y-axis represents the estimated inventory value. The X-axis varies the participant narcissism for the range of GNS scores that are +/- one standard deviation from the mean. Overall, the regression estimates show low narcissism participants make more conservative inventory estimates, and ones that will not allow the division to meet the profit target (i.e., below the $\$ 800,000$ threshold), regardless of subordinate narcissism. The regression results also show that subordinate narcissism has opposite effects on narcissistic participants. When subordinates exhibit low narcissism, more narcissistic participants make increasingly aggressive inventory estimates that are above the profit target threshold. However, when subordinates exhibit high narcissism, more narcissistic participants make increasingly conservative inventory estimates. These results support H2.

\section{Supplemental tests}

This article is protected by copyright. All rights reserved. 


\section{Sensitivity tests}

We consider two alternative analyses for our primary regression analyses. First, we apply a median split of GNS scores in a 2x2 ANOVA in place of the continuous measure used in the regression analyses. We note that our results for both Hypothesis 1 and Hypothesis 2 (untabulated) are robust. Second, an alternative way to analyze inventory value choices is to categorize the values into those that allow the division to meet or beat the earnings target and those that do not. We conduct an additional test, using logistic regression. We re-code participant inventory values equal to one if they chose a value $\geq \$ 800,000$ (that is, the minimum inventory value that would still allow the division to meet the earnings target), and zero, otherwise. We find results consistent with H2 (untabulated), with the coefficient on SubNarc significantly negative $\left(\beta_{1}=-0.927, \mathrm{p}<0.001\right)$, the coefficient on GNS significantly positive $\left(\beta_{2}=0.018, \mathrm{p}=\right.$ 0.040), and the $\operatorname{SubNarc}^{*}$ GNS interaction marginally significant, and negative $\left(\beta_{3}=-0.018, \mathrm{p}=\right.$ 0.092).

\section{Alternative Explanations}

Narcissists have been shown to exhibit greater risk-taking behavior (Campbell, Goodie, and Foster 2004). This behavior stems from their inflated beliefs about themselves (i.e., overconfidence) and their desire to prove their superiority. Supervisors might discount an aggressive estimate from a narcissistic subordinate to guard against this risk-taking proclivity. Indeed, our results show that supervisors, on average, made larger downward (i.e., conservative) adjustments when the subordinate was narcissistic. However, the risk explanation does not 
account for the interaction between subordinate and supervisor narcissism. Since narcissists are more accepting of risks, narcissistic supervisors should be more willing to permit an aggressive estimate. We observe this only when subordinate narcissism is low. When subordinate narcissism is high, narcissistic supervisors make more conservative inventory estimates.

Another alternative explanation for our results is that narcissists are perceived to be less competent employees, which would provide supervisors a reason to alter their work. However, Judge et al. (2006) found that subordinate narcissism did not influence supervisor ratings of employee job performance. Also, as we will discuss below, the high narcissism subordinate was viewed as more of a career threat than the low narcissism subordinate, which suggests that the high narcissism subordinate was perceived to be at least as competent as the low narcissism subordinate. For these reasons, we believe it is unlikely that our results are attributable to differences in perceived competence of the low/high narcissism subordinate.

Does perceived career threat explain narcissistic hypocrisy?

Bushman and Baumeister (1998) provide evidence that threat perception mediated the relationship between narcissism and aggressive behavior toward an ego threat. To determine if threat perception explains narcissistic supervisors’ larger adjustments to the narcissistic subordinate’s estimate, we asked participants to rate their agreement with this statement: "I would view Casey Jones as a threat to my career,” using a seven-point Likert scale (1 - strongly disagree, 7 - strongly agree). We then tested for mediated moderation, using structural equation 
modeling (SEM), to assess the extent to which perceived career threat mediates the interactive effect of subordinate and supervisor narcissism on inventory estimates ${ }^{9}$.

We used Mplus (Muthén and Muthén 2017) to conduct our analysis. If perceptions of career threat are driving the main result, we should see that narcissistic supervisors are more threatened when a subordinate exhibits narcissism, which, in turn, causes the supervisor to reject the subordinate estimate. The SEM results, including a path diagram are reported in Figure 3.

\section{[INSERT FIGURE 3 HERE]}

The path of interest is the path from SubNarc*GNS $\rightarrow$ Threat $\rightarrow$ Inventory. To be consistent with narcissistic tolerance, the coefficient on the path from SubNarc*GNS to Threat should be positive, and the coefficient from Threat to Inventory should be negative. Since the model is fully saturated, fit statistics are not available. SubNarc*GNS affects Threat in the predicted manner $(\beta=0.020, \mathrm{p}=0.001)$; more narcissistic supervisors rate the narcissistic subordinate as a greater career threat. Threat is also related to Inventory, as predicted ( $\beta=$ 5.317, $\mathrm{p}=0.024)$; supervisors who feel the subordinate is a greater career threat provide lower inventory values. The indirect path from SubNarc*GNS to Inventory, through Threat can be calculated by multiplying the coefficients from SubNarc*GNS to Threat and Threat to Inventory together. A Sobel test reveals the indirect path is not significantly different from zero $(\mathrm{t}=-1.198$,

\footnotetext{
${ }^{9}$ Alternative tests using the Baron and Kenny (1986) regression method, and the Hayes (2012) bootstrapping method yielded the same statistical conclusions.
} 
$\mathrm{p}=0.115$, one-tailed, untabulated). Thus, it does not appear that career threat mediates the interactive effect of supervisors and subordinate narcissism on supervisor inventory estimates ${ }^{10}$.

We speculate that mediation was not successful because the mediator measure specifically asked supervisors to assess the career threat posed by the subordinate, and this did not adequately measure ego threat. Ex-ante, we believed career threat (being surpassed by a subordinate) was likely to be a primary concern given our setting, and a reasonable proxy for ego threat. While the mediation test showed that narcissistic supervisors considered the narcissistic subordinate to be a greater career threat, the actual magnitude of the perceived career threat was minimal. In untabulated analyses, ex post, we found that participants in both the low and high narcissistic subordinate conditions rated career threat below the midpoint of four on the sevenpoint responses scale (means of 2.15 and 3.82 for the low and high narcissistic subordinate conditions, respectively). This suggests that the narcissistic subordinate was not seen as a credible career threat. In retrospect, this is plausible, because the supervisor/subordinate relationship was made apparent. Participants must have felt that there was little career threat from someone who was clearly their junior. However, this does not exclude the narcissistic subordinate from being an ego threat, it just means narcissistic supervisors did not feel threatened in that specific way.

Both the low and high narcissism subordinate were described as educated, ambitious, hardworking, personable, and funny. The high narcissism subordinate was also described (in

\footnotetext{
${ }^{10}$ We also examined likeability, and a measure of perceived similarity between the supervisor and subordinate as potential mediators. We did not find evidence that either measure mediated the main result.
} 
part) as a showoff, who likes the spotlight, believes he is better than others, and is willing to leverage situations to his advantage. This description should have provoked a comparison from narcissistic supervisors, resulting in a threatened ego, and hostility toward the subordinate (Bogart et al. 2004). We believe that ego threat is the underlying cause of our observed narcissistic hypocrisy, and that the career threat measure was simply not an adequate proxy for ego threat. We recognize this as a limitation of our research in our conclusion section.

\section{Conclusion}

As a safeguard to financial reporting quality, supervisors are tasked with reviewing accounting estimates advanced by subordinates. We use an experiment to demonstrate that supervisor reviews are significantly influenced by subordinate narcissism. Our results also demonstrate that the effect of subordinate narcissism is conditional on supervisor narcissism. We provide evidence of both narcissistic tolerance and narcissistic hypocrisy. On one hand, narcissistic supervisors are more tolerant of narcissistic subordinates, rating them as more likable. On the other hand, narcissistic supervisors are less likely to agree with narcissistic subordinates’ aggressive accounting choices, even when disagreeing leads to falling short of an earnings target.

Our research makes several contributions. Wisse et al. (2015) provided initial evidence of narcissistic hypocrisy in a sample of Dutch supervisors. We demonstrate that narcissistic hypocrisy not only influences narcissists’ perceptions of other narcissists, but also affects narcissists' use of information provided by other narcissists in a meaningful management 
decision-making setting. Our research also contributes to accounting and business research and practice. Most business organizations, including professional accounting practices, exhibit a hierarchal structure. In such organizations, managers leverage and rely on the work of subordinate professionals. We demonstrate the importance of subordinates and their personalities in the development of accounting information. Subordinate narcissism is particularly relevant because research suggest that narcissism is increasing in younger populations (Twenge et al. 2008; Young et al. 2016). While most of the prior accounting literature focuses on the personal characteristics of executives or primary decision makers, we provide evidence that subordinates, and their personalities, can exert significant influence over the financial reporting process.

We made several significant design choices which limit the conclusions that can be drawn from our work. Perhaps most importantly, we utilized written descriptions to manipulate subordinate narcissism. While this is consistent with prior work in the area, and allows for greater experimental control, and internal validity, we do sacrifice contextual richness that is present in real life. This is most notable in two ways. First, work relationships are built over time, and across many interactions. Other research on narcissism has suggested that perceptions of narcissists may change over time (e.g., Paulhus 1998). Narcissistic hypocrisy could be moderated by the nature, and/or duration of the relationship between the supervisor and subordinate. However, we note that our results are consistent with Wisse, et al. (2015), who measured narcissism in actual pairs of supervisors/subordinates, and still found evidence consistent with narcissistic hypocrisy. Second, personalities are multi-faceted. Narcissists are not 
only narcissistic. Many researchers have noted the correlation between narcissism and two other traits, Machiavellianism and psychopathy (Dahling, Whitaker, and Levy 2009; Jonason and Webster 2010; Rauthmann 2012; Rauthmann and Kolar 2013). While there is some overlap between narcissism, Machiavellianism, and psychopathy, our manipulation was not meant to create a multi-faceted personality including Machiavellianism and Psychopathy. It is possible that the relative strength of these related traits (or other traits) within a fully formed personality could alter how one is perceived by others.

Another limitation of our work is our focus on a single type of narcissism (namely, grandiose narcissism), and our use of a specific measure of grandiose narcissism (specifically, the GNS). Narcissism is a complex construct. There is evidence of significant variation, within narcissists, on several different dimensions (e.g., Dickinson and Pincus 2003; Foster and Campbell 2007; Back, et al. 2013; Kwiatkowska, et al. 2019). A host of scales exists that vary in length (e.g., 13 - 40 questions), format (e.g., force choice versus use of Likert scales), structure (yielding $2-7$ sub-factors), and theoretical underpinnings (e.g., grandiose versus vulnerable narcissism). It is possible that some forms of narcissism are more/less conducive to narcissistic hypocrisy, as different forms of narcissism may be more or less compatible with each other. It also seems likely that the amount of narcissistic hypocrisy may be exacerbated by certain variations of narcissists (such as vulnerable narcissists). We leave it to future researchers to investigate these possibilities. Additionally, we explored a specific behavior (namely, managing earnings upwards), absent any true financial or career motives for engaging in the behavior. 
Narcissistic hypocrisy may be heightened or attenuated when incentives such as financial rewards, job security, and or workplace recognition are present.

A final limitation of our study is that we did not find evidence that threat perception mediates the narcissistic hypocrisy effect. As previously discussed, we believe this lack of finding is attributable to mismeasurement of the construct (i.e., career threat versus ego threat) rather than a theoretical issue. However, we cannot rule out the possibility that narcissistic hypocrisy is caused by something other than ego threat. Future researchers could help clarify this no-result by incorporating more nuanced measures of ego threat perception. 


\section{References}

Ackerman, R. A., E. A. Witt, M. B. Donnellan, K. H. Trzesniewski, R. W. Robins, and D. A. Kashy. 2011. What does the Narcissistic Personality Inventory really measure? Assessment 18 (1):67-87.

Adams, J. M., W. Hart, and K. A. Burton. 2015. I only like the idea of you: Narcissists tolerate others' narcissistic traits but not their corresponding behaviors. Personality and Individual Differences 82:232-236.

Ahmed, A. S., and S. Duellman. 2013. Managerial overconfidence and accounting conservatism. Journal of Accounting Research 51 (1):1-30.

Baron, Reuben M, and David A Kenny. 1986. "The moderator-mediator variable distinction in social psychological research: Conceptual, strategic, and statistical considerations." Journal of personality and social psychology 51 (6):1173.

Back, M. D., A. C. Küfner, M. Dufner, T. M. Gerlach, J. F. Rauthmann, and J. J. Denissen. 2013. Narcissistic admiration and rivalry: Disentangling the bright and dark sides of narcissism. Journal of personality and social psychology 105 (6):1013.

Baumeister R., L. Smart and M. 1996. Relation of threatened egotism to violence and aggression: The dark side of high self-esteem. Psychological Review 103:5-33.

Blair, C. A., B. J. Hoffman, and K. R. Helland. 2008. Narcissism in organizations: A multisource appraisal reflects different perspectives. Human Performance 21 (3):254-276.

Bogart, L., E. Benotsch and J. Pavlovic. 2004. Feeling superior but threatened: The relation of narcissism to social comparison. Basic and Applied Social Psychology, 26(1): 35-44.

Braun, S., N. Aydin, D. Frey, and C. Peus. 2018. Leader narcissism predicts malicious envy and supervisor-targeted counterproductive work behavior: Evidence from field and experimental research. Journal of Business Ethics 151 (3):725-741.

Buffardi, L. E., and W Keith Campbell. 2008. "Narcissism and social networking web sites." Personality and social psychology bulletin 34 (10):1303-1314.

Burton, K. A., J. M. Adams, W. Hart, B. Grant, K. Richardson, and G. Tortoriello. 2017. You remind me of someone awesome: Narcissistic tolerance is driven by perceived similarity. Personality and Individual Differences 104:499-503.

This article is protected by copyright. All rights reserved. 
Bushman, Brad J, and Roy F Baumeister. 1998. "Threatened egotism, narcissism, self-esteem, and direct and displaced aggression: Does self-love or self-hate lead to violence?" Journal of personality and social psychology 75 (1):219.

Campbell, W Keith, Adam S Goodie, and Joshua D Foster. 2004. "Narcissism, confidence, and risk attitude." Journal of behavioral decision making 17 (4):297-311.

Corry, N., R. D. Merritt, S. Mrug, and B. Pamp. 2008. The factor structure of the Narcissistic Personality Inventory. Journal of Personality Assessment 90 (6):593-600.

Committee of Sponsoring Organizations of the Treadway Commission (COSO). 2009. Guidance on Monitoring Internal Control Systems. Durham, NC: AICPA. . 2013. Internal Control-Integrated Framework. Durham, NC: AICPA.

Dahling, J. J., Brian G Whitaker, and Paul E Levy. 2009. "The development and validation of a new Machiavellianism scale." Journal of management 35 (2):219-257.

Dickinson, K. A., and A. L. Pincus. 2003. Interpersonal analysis of grandiose and vulnerable narcissism. Journal of personality disorders 17 (3):188-207.

Foster, J. D., and W Keith Campbell. 2007. "Are there such things as "narcissists” in social psychology? A taxometric analysis of the Narcissistic Personality Inventory." Personality and Individual Differences 43 (6):1321-1332.

Foster, J. D., W. K. Campbell, and J. M. Twenge. 2003. Individual differences in narcissism: Inflated self-views across the lifespan and around the world. Journal of research in personality 37 (6):469-486.

Foster, J. D., J. L. McCain, M. F. Hibberts, A. B. Brunell, and R. B. Johnson. 2015. The grandiose narcissism scale: a global and facet-level measure of grandiose narcissism. Personality and Individual Differences 73:12-16.

Friedman, J.N.W., T. F. Oltmanns, and E. Turkheimer. 2007. "Interpersonal perception and personality disorders: Utilization of a thin slice approach." Journal of Research in Personality 41 (3):667-688.

This article is protected by copyright. All rights reserved. 
Grijalva, E., P. D. Harms, D. A. Newman, B. H. Gaddis, and R. C. Fraley. 2015a. Narcissism and leadership: A meta-analytic review of linear and nonlinear relationships. Personnel Psychology 68 (1):1-47.

Grijalva, E., D. A. Newman, L. Tay, M. B. Donnellan, P. D. Harms, R. W. Robins, and T. Yan. 2015b. "Gender differences in narcissism: A meta-analytic review." Psychological bulletin 141 (2):261.

Ham, C., M. Lang, N. Seybert, and S. Wang. 2017. CFO narcissism and financial reporting quality. Journal of Accounting Research.

Hampton, C. 2015. "Estimating and reporting structural equation models with behavioral accounting data." Behavioral research in accounting 27 (2):1-34.

Hart, W., and J. M. Adams. 2014. Are narcissists more accepting of others' narcissistic traits? Personality and Individual Differences 64:163-167.

Hayes, Andrew F. 2013. Introduction to mediation, moderation, and conditional process analysis: A regression-based approach: Guilford Press.

Jia, Y., L. V. Lent, and Y. Zeng. 2014. Masculinity, testosterone, and financial misreporting. Journal of Accounting Research 52 (5):1195-1246.

Johnson, E. N., J. R. Kuhn Jr, B. A. Apostolou, and J. M. Hassell. 2012. Auditor perceptions of client narcissism as a fraud attitude risk factor. Auditing: A Journal of Practice \& Theory 32 (1):203-219.

Johnson, E. N., L. A. Kidwell, D. J. Lowe, and P. M. J. Reckers. 2019. "Who Follows the Unethical Leader? The Association Between Followers' Personal Characteristics and Intentions to Comply in Committing Organizational Fraud." Journal of Business Ethics 154 (1):181-193.

Jonason, P. K., and G. D. Webster. 2010. "The dirty dozen: a concise measure of the dark triad." Psychological assessment 22 (2):420.

Jones, D. N., and D. L. Paulhus. 2010. Different provocations trigger aggression in narcissists and psychopaths. Social Psychological and Personality Science 1 (1):12-18.

Judd, J. S., K. J. Olsen, and J. Stekelberg. 2016. How do Auditors Respond to CEO Narcissism? Evidence from External Audit Fees. Accounting horizons.

This article is protected by copyright. All rights reserved. 
Judge, T. A., J. A. LePine, and B. L. Rich. 2006. Loving yourself abundantly: relationship of the narcissistic personality to self-and other perceptions of workplace deviance, leadership, and task and contextual performance. Journal of Applied Psychology 91 (4):762.

Kwiatkowska, M. M., T. Jułkowski, R. Rogoza, M. Żemojtel-Piotrowska, and R. Fatfouta. 2019. "Narcissism and trust: Differential impact of agentic, antagonistic, and communal narcissism." Personality and Individual Differences 137:139-143.

Lipe, M. G. 2018. Unpacking the disclosure package: Using experiments to investigate investor reactions to narrative disclosures. Accounting, Organizations and Society.

Maccoby, M. 2000. Narcissistic leaders: The incredible pros, the inevitable cons. Harvard Business Review 78 (1):68-78.

Miller, J. D., B. J. Hoffman, E. T. Gaughan, B. Gentile, J. Maples, and W. Keith Campbell. 2011. Grandiose and vulnerable narcissism: A nomological network analysis. Journal of personality 79 (5):1013-1042.

Miller, J. D., D. R. Lynam, C. S. Hyatt, and W. K. Campbell. 2017. Controversies in narcissism. Annual Review of Clinical Psychology 13:291-315.

Murphy, P. R. 2012. Attitude, Machiavellianism and the rationalization of misreporting. Accounting, Organizations and Society 37 (4):242-259.

Olsen, K. J., K. K. Dworkis, and S. M. Young. 2013. CEO narcissism and accounting: A picture of profits. Journal of Management Accounting Research 26 (2):243-267.

Olsen, K. J., and J. Stekelberg. 2015. CEO narcissism and corporate tax sheltering. The Journal of the American Taxation Association 38 (1):1-22.

Paulhus, D. L. 1998. "Interpersonal and intrapsychic adaptiveness of trait self-enhancement: A mixed blessing?" Journal of personality and social psychology 74 (5):1197.

Paulhus, D. L. 2014. Toward a taxonomy of dark personalities. Current Directions in Psychological Science 23 (6):421-426.

Raskin, R., and H. Terry. 1988. A principal-components analysis of the Narcissistic Personality Inventory and further evidence of its construct validity. Journal of personality and social psychology 54 (5):890.

This article is protected by copyright. All rights reserved. 
Rauthmann, J. F. 2012. "The Dark Triad and interpersonal perception: Similarities and differences in the social consequences of narcissism, Machiavellianism, and psychopathy." Social Psychological and Personality Science 3 (4):487-496.

Rauthmann, J. F, and G. P. Kolar. 2013. "Positioning the Dark Triad in the interpersonal circumplex: The friendly-dominant narcissist, hostile-submissive Machiavellian, and hostile-dominant psychopath?" Personality and Individual Differences 54 (5):622-627.

Rosenthal, S. A., and T. L. Pittinsky. 2006. Narcissistic leadership. The Leadership Quarterly 17 (6):617-633.

Schrand, C. M., and S. L. Zechman. 2012. Executive overconfidence and the slippery slope to financial misreporting. Journal of accounting and economics 53 (1):311-329.

Twenge, J. M., and S. M. Campbell. 2008. Generational differences in psychological traits and their impact on the workplace. Journal of Managerial Psychology 23 (8):862-877.

Twenge, J. M., and J. D. Foster. 2010. Birth cohort increases in narcissistic personality traits among American college students, 1982-2009. Social Psychological and Personality Science 1 (1):99-106.

Twenge, J. M., S. Konrath, J. D. Foster, W. Keith Campbell, and B. J. Bushman. 2008. Egos inflating over time: A cross-temporal meta-analysis of the Narcissistic Personality Inventory. Journal of personality 76 (4):875-902.

Wallace, H. M., A. Grotzinger, T. J. Howard, and N. Parkhill. 2015. When people evaluate others, the level of others' narcissism matters less to evaluators who are narcissistic. Social Psychological and Personality Science 6 (7):805-813.

West, S. G., L. S. Aiken, and J. L. Krull. 1996. Experimental personality designs: Analyzing categorical by continuous variable interactions. Journal of personality 64 (1):1-48.

Wisse, B., D. P. Barelds, and E. F. Rietzschel. 2015. How innovative is your employee? The role of employee and supervisor Dark Triad personality traits in supervisor perceptions of employee innovative behavior. Personality and Individual Differences 82:158-162.

Young, S. M., F. Du, K. K. Dworkis, and K. J. Olsen. 2015. It's All about All of Us: The Rise of Narcissism and Its Implications for Management Control System Research. Journal of Management Accounting Research 28 (1):39-55. 
Vazire, S., L. P. Naumann, P. J. Rentfrow, and S. D. Gosling. 2008. "Portrait of a narcissist: Manifestations of narcissism in physical appearance." Journal of Research in Personality 42 (6):1439-1447.

This article is protected by copyright. All rights reserved. 
TABLE 1

Descriptive Statistics and Spearman Correlations

\begin{tabular}{lccccccc} 
& & & & \multicolumn{3}{c}{ Inventory } & \multicolumn{2}{c}{ Career } \\
Mean & Age & Gender & SubNarc & GNS & Value & Likable & Threat \\
\cline { 2 - 8 } SD & 47.35 & 0.52 & 0.49 & 142.39 & 780.12 & 4.89 & 2.97 \\
n & 15.22 & 0.50 & 0.50 & 26.49 & 90.28 & 1.66 & 1.62 \\
& 254 & 254 & 254 & 254 & 254 & 254 & 254
\end{tabular}

Age

Gender $\quad .287 * *$

SubNarc - $031-023$

GNS $-.258 * * \quad .016$

$\begin{array}{lllll}\text { Inventory Value } \quad .023 & -.008 & -.247 * * & .065\end{array}$

$\begin{array}{lllll}\text { Likable } & -.065 & -.001 & -.698 * * & .018\end{array}$

$\begin{array}{lllllll}\text { Career Threat } & -.044 & .002 & .524 * * & .085 & -.202 * * & -.432 * *\end{array}$

**Correlation significant at 0.01 level (two-tailed)

Gender was coded as 0 - female, 1 - male

Subnarc was coded as 0 - low subordinate narcissism, 1 - high subordinate narcissism

GNS = participant score on the Grandiose Narcissism Scale

Inventory Value = participant inventory value estimate (in thousands of dollars)

Career Threat $=$ participant rating of the subordinate as a career threat $(1-7$ scale $)$

Likability $=$ participant rating of how likable they find the subordinate ( $1-7$ scale)

This article is protected by copyright. All rights reserved. 
TABLE 2

Subordinate Likability

\begin{tabular}{|c|c|c|c|c|}
\hline Variable & Predicted & $\underline{\beta}$ & t-stat & p-value \\
\hline Intercept & & 6.016 & $\overline{57.437}$ & $<0.001$ \\
\hline SubNarc & & -2.330 & -15.621 & $<0.001$ \\
\hline GNS & & $<0.001$ & 0.006 & 0.995 \\
\hline SubNarc * GNS & + & 0.012 & 2.070 & 0.039 \\
\hline $\mathrm{n}$ & & 254 & & \\
\hline $\mathrm{R}^{2}$ & & $50 \%$ & & \\
\hline
\end{tabular}

Likable $=\beta_{0}+\beta_{1}$ SubNarc $+\beta_{2} G N S+\beta_{3}$ SubNarc x GNS

SubNarc $=1(0)$ if the participant was in the high (low) subordinate narcissism condition. GNS = the mean-centered participant GNS score. The dependent variable, Likable = participant rating of the subordinate from the question, "Rate your agreement with the following statement: (The subordinate) is a likable person”, using a 7-point scale from (1 - strongly disagree, 7 - strongly agree). All p-values are two-tailed. Variable definitions are provided in Table 1.

This article is protected by copyright. All rights reserved. 
TABLE 3

Inventory Values

\begin{tabular}{|c|c|c|c|c|}
\hline Variable & Predicted & $\boldsymbol{\beta}$ & $\underline{\text { t-stat }}$ & p-value \\
\hline$\overline{\text { Intercept }}$ & & 801.474 & $1 \overline{103.073}$ & $<0.001$ \\
\hline SubNarc & & -40.710 & -3.676 & $<0.001$ \\
\hline GNS & & 0.660 & 2.047 & 0.042 \\
\hline SubNarc * GNS & - & -0.923 & -2.177 & 0.030 \\
\hline $\mathrm{n}$ & & 254 & & \\
\hline $\mathrm{R}^{2}$ & & $7 \%$ & & \\
\hline
\end{tabular}

SubNarc $=1(0)$ if the participant was in the high (low) subordinate narcissism condition. GNS = the mean-centered participant GNS score. The dependent variable, Inventory = participant choice of inventory value. An inventory value of at least $\$ 800 \mathrm{~K}$ was needed to meet the division profit target. All p-values are two-tailed. Variable definitions are provided in Table 1. 
Figure 1 Plot of Likability Regression Estimates

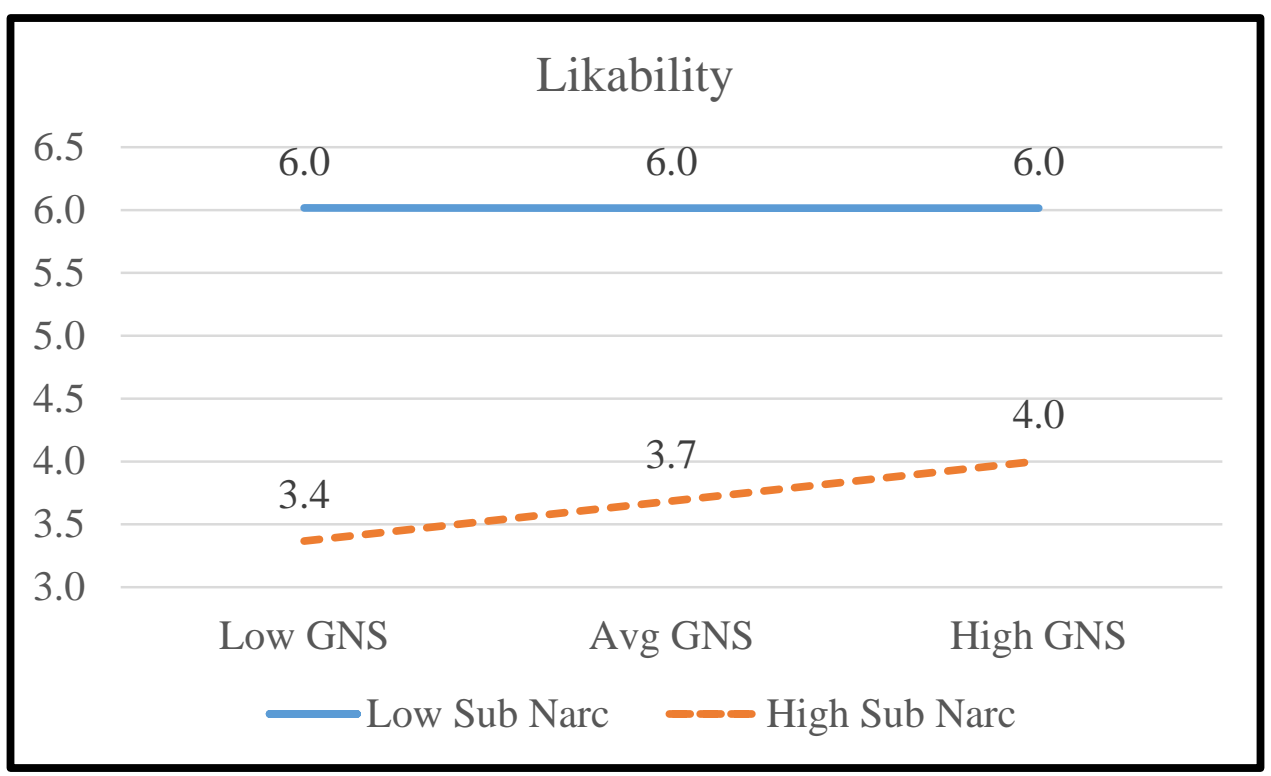

Figure 1 shows predicted mean ratings of subordinate likability based on the regression described in Table 2. Low/High GNS are at -1/+1 standard deviation from the mean GNS score. Variable definitions are provided in Table 1.

This article is protected by copyright. All rights reserved. 
Figure 2 Plot of Inventory Value Regression Estimates

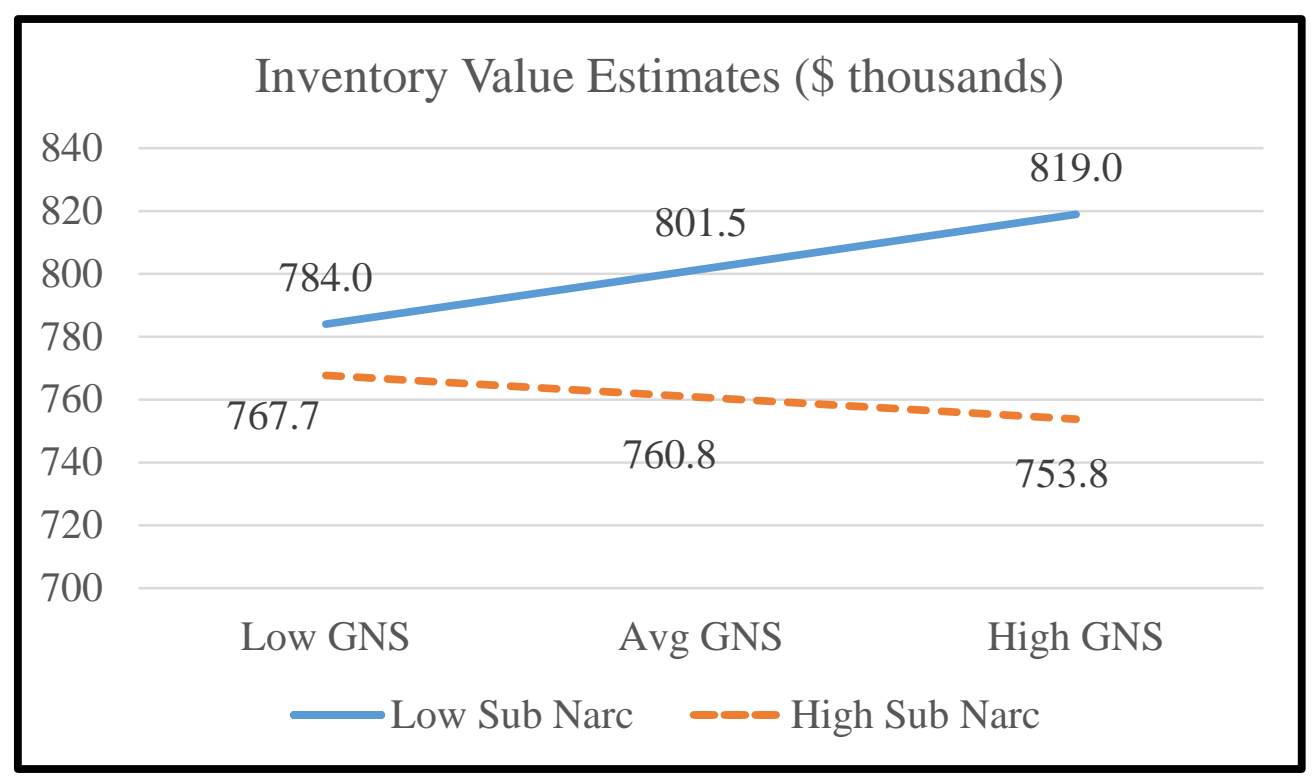

Figure 2 shows predicted mean inventory values based on the regression described in Table 3. Low/High GNS are at -1/+1 standard deviation from the mean GNS score. Variable definitions are provided in Table 1.

This article is protected by copyright. All rights reserved. 
Figure 3 SEM Model 1 (ML Estimation)

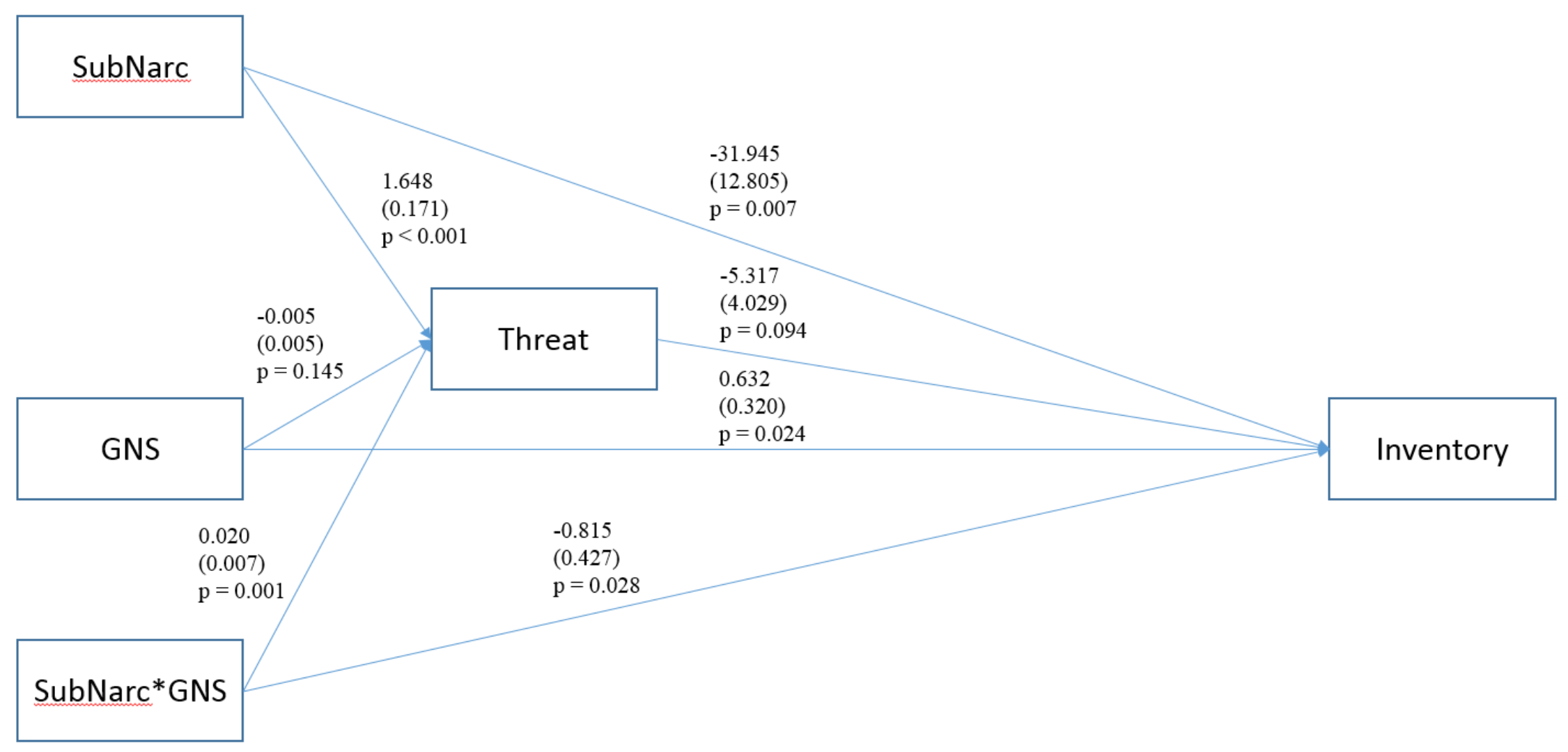

$N=254$

Fit indices - not available for fully saturated models.

This article is protected by copyright. All rights reserved. 
Threat $\mathrm{R}^{2}=0.305$, Inventory $\mathrm{R}^{2}=0.074$

SubNarc $=0$ (1) for low (high) subordinate narcissism

GNS = mean centered participant GNS score

Threat = Participant response to "I would view [the subordinate] as a threat to my career" (1 - 7 scale)

Inventory = Participant inventory dollar value recommendation

Next to each path is, from top to bottom: path coefficient, standard error, and p-value (one-tailed).

This article is protected by copyright. All rights reserved. 


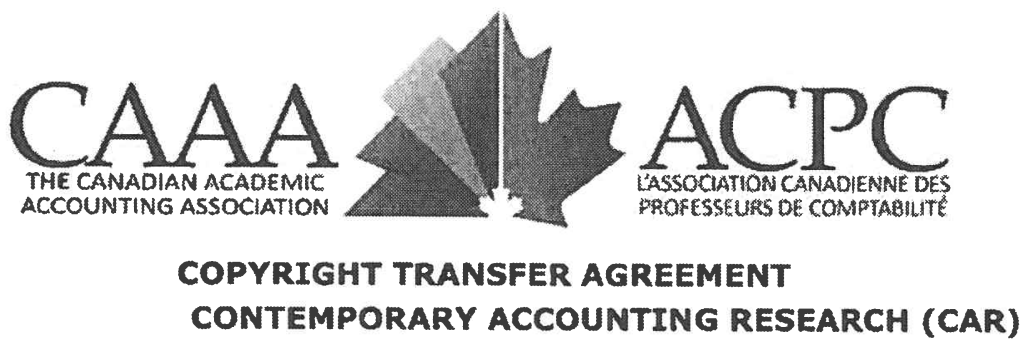

Date: $\tilde{I} / 23 / 19$

Contributor name(s): Mathew J.Hayes, Phili, M. Reckers

Contributor address(es): 19000 Htubbanl Dr. Diarborn, MI, USA 48126

Manuscript number: $2017-312 R 3$

Re: Manuscript entitled The role of narcissistic hypocrisy in the development of (iccanting estimaits "Contribution")

for publication in Contemporary Accounting Research (the "Journal")

published by the Canadian Academic Accounting Association (the "Owner")

Dear Contributor(s):

Thank you for submitting your Contribution for publication. In order to expedite the editing and publishing process and enable the Owner to disseminate your Contribution to the fullest extent, we need to have this Copyright Transfer Agreement executed. If the Contribution is not accepted for publication, or if the Contribution is subsequently rejected, this Agreement shall be null and void.

Publication cannot proceed without a signed copy of this Agreement.

\section{A. COPYRIGHT}

1. In consideration of Owner's publication of the Contribution in the Journal, the Contributor(s) assigns to the Owner, during the full term of copyright and any extensions or renewals, all copyright in and to the Contribution, and all rights therein, including but not limited to the right to publish, republish, transmit, sell, distribute and otherwise use the Contribution in whole or in part in electronic and print editions of the Journal and in derivative works throughout the world, in all languages and in all media of expression now known or later developed, and to license or permit others to do so.

2. Reproduction, posting, transmission or other distribution or use of the final Contribution in whole or in part in any medium by the Contributor as permitted by this Agreement requires a citation to the Journal suitable in form and content as follows: (Title of Article, Contributor, Journal Title and Volume/Issue, Copyright (c) [year], copyright owner as specified in the Journal, Publisher). Links to the final article on the publisher website are encouraged where appropriate.

\section{B. RETAINED RIGHTS}

Notwithstanding the above, the Contributor(s) or, if applicable, the Contributor's employer, retains all proprietary rights other than copyright, such as patent rights, in any process, procedure or article of manufacture described in the Contribution.

\section{PERMITTED USES BY CONTRIBUTOR}

1. Submitted Version. The Owner licenses back the following rights to the Contributor(s) in the version of the Contribution as originally submitted to the Journal for publication:

a. The right to self-archive on the Contributor's personal website, place in a not for profit subject-based preprint server or repository, or in the Contributor's company/ institutional

Please submit this Copyright Transfer Agreement via your Author Login page in Editorial Manager 
repository or archive. This right extends to both intranets and the Internet. The Contributor may not update the submitted version or replace it with the accepted or the published Contribution. The version posted must acknowledge acceptance for publication and, following publication of the final Contribution, contain a legend as follows: This is the pre-peer reviewed version of the following article: FULL CITE, which has been published in final form at [Link to final article]. Contributors are not required to remove preprints posted to not for profit preprint servers prior to submission of the Contribution.

2. Accepted Version. The Owner licenses back the following rights to the Contributor in the version of the Contribution accepted by the Journal for publication:

a. The right to self-archive the peer-reviewed (but not final) version of the Contribution on the Contributor's personal website, in the Contributor's company/institutional repository or archive, and in certain not for profit subject-based repositories such as, but not limited to, PubMed Central as listed at the following website: http://olabout.wiley.com/WilevCDA/Section/id-406074.html, subject to an embargo period of 12 months for scientific, technical and medical (STM) journals and 24 months for social science and humanities (SSH) journals following publication of the final Contribution. There are separate arrangements with certain funding agencies governing reuse of this version as set forth at the following website: http://www.wiley.com/go/funderstatement. Unless otherwise specified, the accepted version of the contribution must be self-archived in accordance with Wiley's Terms and Conditions for Self-Archiving. The Contributor may not update the accepted version or replace it with the published Contribution. The version posted must contain a legend as follows: This is the accepted version of the following article: FULL CITE, which has been published in final form at [Link to final article].

b. The right to transmit, print and share copies with colleagues, provided that there is no systematic distribution of the accepted version, e.g. posting on a listserve, network (including scientific social networks) or automated delivery.

2.1 Accepted Version and Compliance with Open Access Policies on Publications. The Contributor(s) may make a written request of the Owner for a limited license to comply solely as is necessary with section 3 of the open access policy published by the Government of Canada's Canadian Institutes of Health Research (CIHR), the Natural Sciences and Engineering Research Council of Canada (NSERC) and the Social Sciences and Humanities Research Council of Canada (SSHRC): http: / / www.science.gc. ca/default. asp?lang $=E n \& n=F 6765465-1$ or to comply solely as is necessary with any other substantially similar open access policy of a substantially similar government agency ("Open Access Policy"). Such written request shall specify Contributor(s) proposed Open Access Policycompliant use. Owner's decision to grant such license to the Contributor(s) in respect of such specified requested use shall be at its sole discretion, and no such license shall be valid unless it is provided by Owner to the Contributor(s) in writing, in advance.

3. Final Published Version. The Owner hereby licenses back to the Contributor the following rights with respect to the final version of the Contribution published by Wiley Periodicals, Inc.:

a. Copies for colleagues. The personal right of the Contributor only to send or transmit individual copies of the final published version in any format to colleagues upon their specific request provided no fee is charged, and further provided that there is no systematic distribution of the Contribution, e.g. posting on a listserve, network or automated delivery.

b. Re-use in other publications. Subject to the conditions set out in section 4.6 (excluding that pertaining to word count), the right to re-use the final Contribution for any publication authored or edited by the Contributor (excluding journal articles) where such re-used material constitutes less than half of the total material in such publication. In such case, any modifications shall be accurately noted.

c. Teaching duties. The right to include the Contribution in teaching or training duties at the Contributor's institution/place of employment including in course packs, e-reserves, 
presentation at professional conferences, in-house training, or distance learning. The Contribution may not be used in seminars outside of normal teaching obligations (e.g. commercial seminars). Electronic posting of the final published version in connection with teaching/training at the Contributor's company/institution is permitted subject to the implementation of reasonable access control mechanisms, such as user name and password. Posting the final published version on the open Internet is not permitted.

d. Oral presentations. The right to make oral presentations based on the Contribution.

\section{Article Abstracts, Figures, Tables, Data Sets, Artwork and Selected Text (up to 250 words).}

a. Contributors may re-use unmodified abstracts for any non-commercial purpose. For online uses of the abstracts, the Owner encourages but does not require linking back to the final published versions.

b. Contributors may re-use figures, tables, data sets, artwork, and selected text up to 250 words from their Contributions, provided the following conditions are met:

(i) Full and accurate credit must be given to the Contribution.

(ii) Modifications to the figures, tables and data must be noted. Otherwise, no changes may be made.

(iii) The re-use may not be made for direct commercial purposes, or for financial consideration to the Contributor.

(iv) Nothing herein shall permit dual publication in violation of journal ethical practices.

\section{CONTRIBUTIONS OWNED BY EMPLOYER}

1. If the Contribution was written by the Contributor in the course of the Contributor's employment (as a "work-made-for-hire" in the course of employment), the Contribution is owned by the company/institution which must execute this Agreement (in addition to the Contributor's signature). In such case, the company/institution hereby assigns to the Owner, during the full term of copyright, all copyright in and to the Contribution for the full term of copyright throughout the world as specified in paragraph A above.

For company/institution-owned work, signatures cannot be collected electronically and so instead please print off this Agreement, ask the appropriate person in your company/institution to sign the Agreement as well as yourself in the space provided below, and email a scanned copy to the Journal production editor. For production editor contact details, please visit the Journal's online author guidelines.

2. In addition to the rights specified as retained in paragraph $B$ above and the rights granted back to the Contributor pursuant to paragraph $\mathrm{C}$ above, the Owner hereby grants back, without charge, to such company/institution, its subsidiaries and divisions, the right to make copies of and distribute the final published Contribution internally in print format or electronically on the Company's internal network. Copies so used may not be resold or distributed externally. However, the company/institution may include information and text from the Contribution as part of an information package included with software or other products offered for sale or license or included in patent applications. Posting of the final published Contribution by the company/institution on a public access website may only be done with written permission, and payment of any applicable fee(s). Also, upon payment of the applicable reprint fee, the company/institution may distribute print copies of the published Contribution externally. 


\section{E. GOVERNMENT CONTRACTS}

In the case of a Contribution prepared under U.S. Government contract or grant, the U.S. Government may reproduce, without charge, all or portions of the Contribution and may authorize others to do so, for official U.S. Government purposes only, if the U.S. Government contract or grant so requires. (U.S. Government, U.K. Government, and other government employees: see notes at end.)

\section{F. COPYRIGHT NOTICE}

The Contributor and the company/institution agree that any and all copies of the final published version of the Contribution or any part thereof distributed or posted by them in print or electronic format as permitted herein will include the notice of copyright as stipulated in the Journal and a full citation to the Journal.

\section{G. CONTRIBUTOR'S REPRESENTATIONS}

The Contributor(s) represents that the Contribution is the Contributor's original work. If the Contribution was prepared jointly, all individuals identified as Contributors actually contributed to the Contribution, and all individuals who contributed are included. The Contribution is submitted only to this Journal and has not been published before. (If excerpts from copyrighted works owned by third parties are included, the Contributor(s) will obtain written permission from the copyright owners for all uses as set forth in the Journal's Instructions for Contributors, and show credit to the sources in the Contribution.) The Contributor(s) also warrants that the Contribution contains no libelous or unlawful statements, does not infringe upon the rights (including without limitation the copyright, patent or trademark rights) or the privacy of others, or contain material or instructions that might cause harm or injury. The Contributor(s) further warrants that there are no conflicts of interest relating to the Contribution, except as disclosed. The Contributor (or in the case of jointly prepared Contribution, the Contributors) shall indemnify and hold the Owner harmless from any and all claims, damages, liabilities, costs and expenses (including counsel fees) that the Owner incurs or sustains arising out of any breach by the Contributor(s) of the foregoing warranties. If the term "Contributor" as used herein refers to more than one person, the obligations of the Contributor shall be both joint and several.

\section{H. GOVERNING LAW}

Regardless of its place of physical execution or performance, the provisions of this Copyright Transfer Agreement shall in all respects be construed according to, and the rights and liabilities of the parties hereto shall in all respects be governed by, the laws of the Province of Ontario and the federal laws of Canada applicable therein. The parties hereto attorn to the jurisdiction of the courts of Ontario.

By signing below, I agree to the COPYRIGHT TRANSFER AGREEMENT as shown above.

Contributor's signature: Watth of Hayo

Type or print name here: Mathew J. Hayes

Date: $7 / 23 / 19$

By signing below, we each agree to the COPYRIGHT TRANSFER AGREEMENT as shown above.

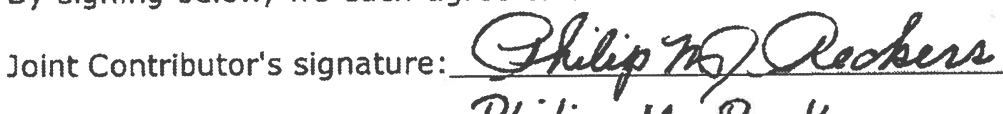

Type or print name here:_Philip M. Reckers

Date:

22 July 2019

Please submit this Copyright Transfer Agreement via your Author Login page in Editorial Manager
The Canadian Academic Accounting Association 1800-80 Bloor St W. Toronto, ON. M5S 2 V1 $+1(416) 486-5361$

This article is protected by copyright. All rights reserved. 
Joint Contributor's signature:

Type or print name here:

Date:

Joint Contributor's signature:

Type or print name here:

Date:

\section{SEKECT FROM OPTIONS BELOW: $\nabla$ Contributor-owned work}

\section{U.S. Government work}

Note to U.S. Government Employees

A contribution prepared by a U.S. federal government employee as part of the employee's official duties, or which is an official U.S. Government publication, is called a "U.S. Government work", and is in the public domain in the United States. In such case, Paragraph A.1 will not apply but the Contributor must type his/her name (in the Contributor's signature line) above. Contributor acknowledges that the Contribution will be published in the United States and other countries. If the Contribution was not prepared as part of the employee's duties or is not an official U.S. Government publication, it is not a U.S. Government work.

\section{U.K. Government work (Crown Copyright)}

Note to U.K. Government Employees

For Crown Copyright this form cannot be completed electronically and should be printed off, signed in the Contributor's signatures section above by the appropriately authorized individual and returned to the Journal production editor by email. For production editor contact details, please visit the Journal's online author guidelines. The rights in a contribution prepared by an employee of a U.K. government department, agency or other Crown body as part of his/her official duties, or which is an official government publication, belong to the Crown. Contributors must ensure they comply with departmental regulations and submit the appropriate authorization to publish. If your status as a government employee legally prevents you from signing this Agreement, please contact the Journal production editor.

Other Including Other Government work or Non-Governmental Organization work Note to Non-U.S., Non-U.K. Government Employees or Non-Governmental Organization Employees For Other Government or Non-Governmental Organization work this form cannot be completed electronically and should be printed off, signed in the Contributor's signatures section above by the appropriately authorized individual and returned to the Journal production editor by email. For production editor contact details, please visit the Journal's online author guidelines. If you are employed by the Department of Veterans Affairs in Australia, the World Bank, the International Monetary Fund, the European Atomic Energy Community, the Jet Propulsion Laboratory at California Institute of Technology, or are a Canadian Government civil servant, please download a copy of the appropriate license agreement from http://authorservices. wiley.com/bauthor/faqs_copyright.asp and return it to the Journal production editor. If your status as a government or non-governmental organization employee legally prevents you from signing this Agreement, please contact the Journal production editor.

Name of Government/Non-Governmental Organization:

Please submit this Copyright Transfer Agreement via your Author Login page in Editorial Manager
The Canadian Academic Accounting Association 1800-80 Bloor St W., Toronto, ON.

M5S 2V1 +1 (416) 486-5631

This article is protected by copyright. All rights reserved. 
Company/institution owned work (made for hire in the course of employment) For "work made for hire" this form cannot be completed electronically and should be printed off, signed and returned to the Journal production editor by email. For production editor contact details, please visit the Journal's online author guidelines. If you are an employee of Amgen, please download a copy of the company addendum from

http://authorservices. wiley.com/bauthor/fags copyright.asp and return your signed license agreement along with the addendum.

Name of Company/Institution:

Authorized Signature of Employer:

Date:

Signature of Employee:

Date:

Please submit this Copyright Transfer Agreement via your Author Login page in Editorial Manager
The Canadian Academic Accounting Association 1800-80 Bloor St W., Toronto, ON.

M5S 2 V1 +1 (416) 486-5631

This article is protected by copyright. All rights reserved. 


\title{
The Role of Narcissistic Hypocrisy in the Development of Accounting Estimates*
}

\author{
Matthew J. Hayes, Assistant Professor ${ }^{\dagger}$ \\ College of Business \\ University of Michigan - Dearborn \\ Philip Reckers, Professor \\ School of Accoutancy, WP Carey School of Business \\ Arizona State University
}

\begin{abstract}
* Accepted by Susan Krische. This paper is based on Professor Hayes' dissertation completed at Arizona State University. He would like to thank his dissertation committee: Phil Reckers (Chair), Jordan Lowe, and Eldar Maksymov for their guidance, and also acknowledge Mike Mowchan, Artur Hugon, Michal Matějka, Stacey Whitecotton, Lucile Faurel, Phil Drake, Don Lange, and Berthold Herrendorf for their assistance and support, as well as workshop participants at Arizona State, Ivey Business School, and the University of Michigan - Dearborn, and financial support from the University of Michigan - Dearborn. The authors would also like to thank Susan Krische and two anonymous reviewers for their helpful comments and suggestions. Data available upon request.

$\dagger$ Corresponding author: 19000 Hubbard Drive, Dearborn, MI 48126, 313-593-5247, hayesmj@umich.edu
\end{abstract}


The Role of Narcissistic Hypocrisy in the Development of Accounting Estimates

\begin{abstract}
In an experiment including experienced managers, we investigate how supervisor and subordinate narcissism influence a supervisor's review of a subordinate's accounting estimate. While narcissistic supervisors express greater liking for narcissistic subordinates (narcissistic tolerance), they nonetheless reject and revise the accounting estimates of narcissistic subordinates to a greater extent than they reject estimates of non-narcissistic subordinates (narcissistic hypocrisy), even when doing so inhibits the supervisor's ability to reach a profit target. Our findings contribute to extant research in accounting and psychology. We demonstrate that narcissistic hypocrisy extends beyond the evaluation of others, and alters narcissists' willingness to rely on other narcissists in a meaningful financial reporting decision. We also find that narcissistic hypocrisy is robust across age, gender and supervisory experience.
\end{abstract}

Keywords: narcissism, narcissistic tolerance, narcissistic hypocrisy, accounting estimates 


\section{The Role of Narcissistic Hypocrisy in the Development of Accounting Estimates}

\section{Introduction}

The integrity of accounting information depends on a system of effective quality controls advanced by a program of checks and balances (COSO 2013). For example, an accounting estimate initiated by a subordinate staff member must be reviewed (i.e., approved or revised) by a supervisor before it is recorded. The review serves to detect and correct potential material misstatements. However, the effectiveness of the review depends on the supervisor's ability to maintain objectivity (COSO 2009). We investigate how both supervisor and subordinate narcissism will influence this review and, specifically, how supervisor reliance on subordinate work will be affected. ${ }^{1}$ Many researchers have previously examined the organizational effects of narcissistic executives (e.g., Olsen, Dworkis, and Young 2013; Olsen and Stekelberg 2015; Ham, et al. 2017; Judd, Olsen, and Stekelberg 2017), including the actions of subordinates in response to executive narcissism (Braun et al. 2018). We believe we are among the first to examine how subordinate narcissism influences supervisors, as well as the interaction between supervisor and subordinate narcissism.

There is ample evidence to suggest narcissism is on the rise in the U.S. population (Twenge et al 2008; Twenge and Campbell 2008; Twenge and Foster 2010), and with it, researchers' interest in the manifold effects of narcissism (Young et al. 2016). Much of this research has focused on the negative impact of narcissism (Johnson et al. 2012; Olsen et al. 2013; Paulhus 2014; Olsen and Stekelberg 2015; Judd et al. 2016; Ham et al. 2017). Typically,

\footnotetext{
${ }^{1}$ We examine grandiose narcissism, characterized by grandiosity, entitlement, extroversion, attention-seeking, authoritativeness, and exploitativeness (Miller et al. 2011). Unless otherwise specified, references to "narcissism" in the manuscript are to grandiose narcissism.
} 
these studies find executive narcissism is associated with untoward executive behavior, such as greater earnings management (Olsen et al. 2013; and Ham et al. 2017).

There is also a growing literature on how narcissistic executives influence individuals within an organization. For example, Braun et al. (2018) find that subordinates have negative emotional reactions to leader narcissism, resulting in increased counterproductive work behavior. However, there is a paucity of studies examining supervisors' reactions to subordinate narcissism, and the interaction of supervisor and subordinate narcissism. Wisse, Barelds, and Rietzschel (2015) provide some evidence on this matter. They find that narcissistic subordinates are rated as more innovative by their supervisors. However, these ratings are moderated by supervisor narcissism; narcissistic supervisors rate narcissistic subordinates as less innovative. We extend this line of research by examining supervisors' use of subordinate input, rather than merely supervisors' perceptions (i.e., evaluations) of subordinates. Our approach allows us to examine the extent to which managers' impressions affect their actions and identify a tangible outcome of the interaction between narcissistic personalities that has implications for reporting quality.

We test whether subordinate narcissism will influence a supervisor's reliance on input from that subordinate. We expect reliance will depend on the supervisor's own narcissism. If this is the case, varying degrees of supervisor and subordinate narcissism may adversely affect reporting quality. This may especially be the case with respect to accounting estimates. Estimates are subjective by their very nature, and negative or positive framing of subordinate input may impair information integrity.

Our hypotheses leverage prior studies advancing the co-existing theories of narcissistic tolerance (i.e., narcissists are more accepting of other narcissists' traits) and narcissistic 
hypocrisy (i.e., despite this professed acceptance, narcissists do not demonstrate tolerance of narcissistic actions directed toward them). Hart and Adams (2014) find that narcissists (relative to non-narcissists) rate others exhibiting narcissistic traits more positively. They call this conditional liking narcissistic tolerance, and it appears to be driven by perceived similarity to self (Burton et al. 2017). Several studies report findings consistent with narcissistic tolerance (e.g., Wallace et al. 2015; Burton et al. 2017). However, Adams, Hart, and Burton (2015) provide evidence of narcissistic hypocrisy. They find that, while narcissists appear to like the idea of a narcissistic other, they are not receptive of others acting narcissistically.

One explanation for narcissistic hypocrisy is that narcissists are protective of their grandiose self-images and are likely to aggress against those who threaten their egos (Bushman and Baumeister 1998; Jones and Paulhus 2010; Wisse, et al. 2015). This is highly relevant in a competitive workplace, where narcissists might be especially sensitive to being outshone. Even though narcissistic supervisors may appear to have a "soft spot" for narcissistic subordinates, they may be less supportive of other narcissists that they view as potential threats.

Using experimental methods, we examine the influence of supervisor and subordinate narcissism on a supervisor's review of a subordinate's proposed inventory write-down for estimated obsolescence. Participants role-play a division manager, who is responsible for reviewing a proposed inventory write-down. The discretionary nature and inherent ambiguity of an inventory valuation allow for a range of acceptable estimates and greater latitude in judgment. In all cases, the subordinate provides an income-favorable estimate for the write-down (i.e., a smaller write-down), which allows the division to meet a profit target. We manipulate the description of the subordinate providing the estimate, as exhibiting high or low narcissism, 
holding knowledge, skill, and ability constant. We measure participant narcissism using the Grandiose Narcissism Scale (Foster et al. 2015).

Our findings provide evidence of both narcissistic tolerance and narcissistic hypocrisy. Compared to supervisors low in narcissism, supervisors high in narcissism rate a narcissistic subordinate as more likable (consistent with narcissistic tolerance); however, this tolerance does not extend to acceptance of the subordinate's recommendation. We find a significant interaction between supervisor and subordinate narcissism, where narcissistic supervisors make larger, income-decreasing adjustments to the proposed estimates of narcissistic subordinates (consistent with narcissistic hypocrisy). Our results are robust to controlling for supervisor age, gender and supervisory experience.

We corroborate and extend prior research by examining not only how narcissistic supervisors perceive narcissistic subordinates, but also how subordinate narcissism influences supervisors' reliance on their work. We confirm that narcissistic supervisors rate narcissistic subordinates more favorably (exhibiting narcissistic tolerance). We extend recent research by documenting an interactive effect of supervisor and subordinate narcissism, resulting in narcissistic hypocrisy that goes beyond personal evaluations. Narcissistic supervisors make greater revisions to narcissistic subordinates' recommendations, even when those revisions impede the achievement of an earnings goal.

Our research contributes to the accounting, management, and psychology literatures. Our findings emphasize the collaborative nature of financial reporting and highlight the importance of interpersonal interactions in accounting decisions. While prior accounting studies have focused on the relationship between executive personality characteristics (including narcissism) and reporting quality (e.g., Murphy 2012; Schrand and Zechman 2012; Ahmed and Duellman 
2013; Olsen et al. 2013; Jia, Lent, and Zeng 2014), our work suggests the study of narcissism should not be restricted to the traits of top-level managers and top-down effects. We demonstrate that subordinate narcissism has a bottom-up effect and that both supervisor and subordinate narcissism have a significant influence on supervisors' reliance on the work of subordinates.

We also contribute to the psychology and management literatures by demonstrating the effect of narcissistic hypocrisy on a business decision. Prior research in this area is concentrated on how narcissists evaluate other narcissists. We provide evidence that the favorable attitudes of narcissistic supervisors towards narcissistic subordinates does not spill over to greater reliance on their work product. To the contrary, our evidence suggests narcissistic hypocrisy results in narcissistic supervisors making significant revisions to input provided by narcissistic subordinates.

The remainder of the paper proceeds as follows: Section II discusses the development of our hypotheses, Section III explains our methodology and experimental design, Section IV reports the results of the experiment, and Section $\mathrm{V}$ provides a discussion of the results and conclusions of our research.

\section{Background and Hypotheses}

\section{Grandiose narcissism}

Narcissism is a complex construct. Researchers generally agree there are two broad categories of narcissism, grandiose and vulnerable narcissism (Dickinson and Pincus 2003; Miller et al. 2011). Grandiose narcissism, the focus of our paper, is the type more commonly encountered in daily life. Also called overt narcissism, grandiose narcissism is what many would consider as the stereotypical image of narcissism: arrogance, a sense of entitlement, and acclaimseeking and exploitative behavior, with a propensity for self-enhancement. On the other hand, 
vulnerable narcissism is also known as covert, or closet narcissism. While vulnerable narcissists also have a sense of entitlement and high expectations, they hide under less flashy personalities, even coming across as shy or modest (see Johnson, Kidwell, Lowe and Reckers, 2019).

The Narcissistic Personality Inventory (NPI), the most widely used measure of subclinical narcissism, is a measure of grandiose narcissism (Miller et al. 2011, Foster et al. 2015). Raskin and Terry (1998) originally proposed seven underlying factors of grandiose narcissism: 1) authority, 2) self-sufficiency, 3) vanity, 4) superiority, 5) exhibitionism, 6) entitlement, and 7) exploitativeness. There is strong consensus that each of these factors relates to the construct of grandiose narcissism. While the NPI functions acceptably as a global measure of grandiose narcissism, researchers have had problems using it to reliably measure the seven subcomponents (Corry et al. 2008; Ackerman et al. 2011). To address this issue, Foster et al. 2015 created the thirty-three item Grandiose Narcissism Scale (GNS), specifically designed to provide an improved overall measure of grandiose narcissism while also measuring each of the seven subcomponents more reliably. We use the more recent GNS measure in our research.

\section{Narcissism in the workplace}

Narcissists are often perceived favorably because of characteristics such as charisma, personal charm, extroversion, and confidence (Grijalva et al. 2015a). Many successful CEOs, athletes, musicians, and entertainers exhibit characteristics associated with narcissism, such as progressive, fashion forward ideas, confidence, and personal charisma (Maccoby 2000). However, researchers have also linked narcissism to negative and destructive behaviors. These negative behaviors include an abusive management style, excessive risk taking, resisting advice, and lapses in professional or ethical judgment (Rosenthal and Pittinsky 2006). Narcissism among corporate executives has been associated with greater earnings management (Olsen et al. 2013, 
Ham et al. 2017), and aggressive tax avoidance (Olsen and Stekelberg 2015). Studies have also demonstrated that external auditors respond negatively to narcissism in client executives by increasing assessments of fraud risk (Johnson et al. 2012), and audit fees (Judd et al. 2017), implying that narcissism is not universally perceived positively.

While there is a significant literature on narcissistic leaders, there is less research on the effects of narcissism in subordinates. Relevant to our work, Blair et al. (2008) measured narcissism in a sample of executive MBA students, and then had each of the students' immediate work-place supervisors and subordinates complete performance appraisals. They found narcissism was correlated with lower ratings of integrity and interpersonal skills from supervisors but was uncorrelated to ratings on the same dimensions from subordinates. Similarly, Judge, LePine, and Rich (2006) found that subordinate narcissism was positively related to supervisor ratings of employee workplace deviance (i.e., counterproductive behaviors, such as not following instructions). These studies suggest supervisors may view narcissistic subordinates more negatively, but neither study measured both supervisor and subordinate narcissism.

We found only one study that examined the interactive effect of supervisor and subordinate narcissism. Wisse et al. (2015) examined how narcissistic supervisors rated the innovativeness of narcissistic subordinates. They found that supervisors rated more narcissistic subordinates as more innovative, but ratings were moderated by supervisor narcissism. Narcissistic supervisors rated narcissistic subordinates as less innovative. We aim to expand the research on narcissistic supervisors and subordinates by examining not only narcissistic supervisor perceptions of narcissistic subordinates, but also the degree to which narcissistic supervisors rely (or do not rely) on the work of narcissistic subordinates. Our research will shed 
light on how the interaction of narcissistic personalities in supervisors and subordinates can affect the financial reporting process.

\section{Narcissistic Tolerance}

There are several studies in the broader social psychology literature examining narcissists' reactions toward other narcissists. Hart and Adams (2014) is an example of one study demonstrating narcissists' favorable response to other narcissists. They measured narcissism in a large pool of undergraduate students, and subsequently had the students rate the likability of a series of hypothetical people possessing one of eleven different traits associated with narcissism (e.g., aggressive, arrogant, flashy), as well as the extent to which the students' believed they themselves possessed those same traits. They found that narcissistic individuals rated others possessing narcissistic traits more positively. Further, they found that students' liking of narcissistic others positively correlated with how strongly the students believed they possessed narcissistic traits, and this measure of self-possession of narcissistic traits mediated the relationship between student narcissism and ratings of other narcissists. They conclude that narcissistic tolerance appears to be driven by perceived similarity.

Wallace et al. (2015) and Burton et al. (2017) replicated the findings of Hart and Adams (2014) under different conditions. Wallace et al. (2015) created profiles of narcissistic and nonnarcissistic individuals based on NPI items (e.g., "I am an extraordinary person”), and asked participants to rate the extent to which they held a positive view of that person. Overall, participants rated the non-narcissistic profile more favorably. However, when rating the narcissistic profile, high narcissism participants gave higher ratings than low narcissism participants. Burton et al. (2017) created video clips of actors providing narcissistic and nonnarcissistic responses to questions and found similar results. Participants reported higher 
likability ratings for the non-narcissistic response, but when rating the narcissistic response, participants higher in narcissism provided higher likability ratings than participants lower in narcissism. Based on these findings, we predict that narcissistic supervisors will exhibit narcissistic tolerance when evaluating the likability of narcissistic subordinates.

HYPOTHESIS 1: Compared to low narcissism supervisors, supervisors high in narcissism will rate narcissistic subordinates as more likable.

\section{Narcissistic hypocrisy}

A positive view of someone in one aspect of social interaction can spill over into other, unrelated aspects of a relationship (i.e., the "halo effect"). Thus, one might expect that narcissistic supervisors exhibiting a favorable likability for narcissistic subordinates would take a similar favorable attitude toward their work product. However, an alternative possibility is that narcissistic superiors view narcissistic subordinates as ego threats and seek to aggress against them. An ego threat can be anything that threatens one's positive self-image (Leary, et al. 2009). Narcissists' strong desire to maintain their own ego (that is, their grandiose, superior self-image) often leads to aggressive reactions towards perceived ego threats (Bushman and Baumeister 1998; Bogart, Bentosch, and Pavlovic 2004; Jones and Paulhus 2010; Back et al. 2013; Wisse et al. 2015).

Baumeister, Smart, and Boden (1996) proposed that narcissists would be particularly prone to aggressive responses to ego threat because of their inflated self-perceptions and their preoccupation with convincing others of their superiority. Bushman and Baumeister (1998) empirically tested this conjecture by examining how narcissists responded to ego threats (operationalized via an insult). They found that narcissism was associated with more aggressive behavior toward the source of an ego threat, and that perceived threat mediated the relationship 
between narcissism and aggressive behavior. Bogart et al. (2004) examined narcissists' responses to a more subtle, indirect form of ego threat: comparing themselves to others. They observed that narcissists were more inclined to compare themselves to others, and merely comparing themselves to someone they view as an ego threat caused narcissists to experience feelings of hostility. We could not find research explicitly examining narcissists' comparison to other narcissists. However, Adams et al. (2015) found that narcissistic tolerance dissipated when narcissists were confronted with narcissistic behaviors. They termed this narcissistic hypocrisy, and it suggests that narcissists view other narcissists as ego threats.

Wisse et al. (2015) documented a similar effect in a work context; they measured narcissism in 306 supervisor-subordinate pairs of Dutch service workers and had each supervisor rate the subordinates' innovativeness. After finding that narcissistic supervisors rated narcissistic subordinates as less innovative, the authors speculated that this interaction may have been caused by narcissistic supervisors feeling threatened by a subordinate "stealing their thunder." From these studies, we infer that narcissistic hypocrisy is likely to manifest if a narcissistic subordinate is perceived as a threat to a narcissistic supervisor's ego.

These prior findings appear highly relevant to a work environment in which a supervisor must decide whether to rely or not on a subordinate's work. We specifically selected a situation where a supervisor must choose to accept, or adjust, a subordinate's proposed inventory adjustment. By doing so, we believe we focus on common financial reporting matters: reliance on subordinates' work and management of earnings to achieve an earnings target. In our setting, a conservative accounting estimate results in missing the earnings target, but a more aggressive (i.e., income favorable) estimate results in meeting or exceeding the target. On the one hand, if a subordinate suggests a more aggressive estimate, a supervisor may be inclined to agree in order 
to meet the earnings target. However, narcissistic hypocrisy suggests that narcissistic supervisors may view the narcissistic subordinate as an ego threat. As a response to this ego threat, narcissistic supervisors may temper their subordinates' suggestions (i.e., choose to sacrifice the earnings goal in order to secure reputational superiority relative to the narcissistic subordinate). HYPOTHESIS 2: Supervisors who exhibit greater narcissism will make larger negative adjustments to aggressive accounting estimates proposed by subordinates who also exhibit greater narcissism.

\section{Method}

\section{Design and Participants}

We tested our hypotheses in a between-subjects experiment. ${ }^{2}$ Participants role-played as a division manager who was responsible for reviewing and approving an inventory obsolescence estimate advanced by a subordinate. We manipulated the narcissistic attributes of the subordinate who generated the estimate. Participant narcissism was a measured independent variable.

We utilized TurkPrime Panels to recruit participants. This service recruits participants from various online platforms (e.g., SurveyMonkey and Qualtrics). We paid a fee to TurkPrime, which pays the other platforms for access to their "panels" of participants. Studies conducted in this fashion draw participants from several different services. The amount and form of participant compensation varies by service. Frequently used compensation forms include cash, reward points, gift cards, and charitable donations. Neither we nor TurkPrime were able to control or collect participant compensation information, so we cannot determine the average compensation for completing our study. Our cost was $\$ 8$ per respondent.

\footnotetext{
${ }^{2}$ IRB approval was granted for the use of human subjects.
} 
We required participants to reside in the United States, be at least 18 years of age, and hold an MBA degree from a U.S. university. Four hundred and seventeen participants attempted our instrument, 110 participants were disqualified for not having an MBA degree, six participants had to be discarded due to an instrument malfunction (specifically, they were not introduced to the narcissism manipulation), and an additional 47 participants were discarded for failing the manipulation check regarding their perceptions of subordinate narcissism (as described below). We conducted our analyses with the remaining 254 participants. $^{3}$

Prior research has shown that people can effectively identify narcissism in others (e.g., Buffardi and Campbell 2008; Friedman, Oltmanns, and Turkheimer 2008; Vazire, Naumann, Rentfrow, and Gosling 2011). After reading a description of a subordinate employee (manipulated to exhibit characteristics consistent with high/low narcissism), participants were asked to rate their agreement with the statement, "Casey Jones (the subordinate) is narcissistic" using a seven-point Likert scale (1 - strongly disagree, 7 - strongly agree). ${ }^{4}$

The 254 participants retained in our analyses took an average of 10.5 minutes to complete the instrument. The average participant was 47 years-old, the sample was $52 \%$ male, and 80 percent of participants reported having managerial experience, with an average of 13.7 years (SD $=11.7$ ) of experience. Libby, Bloomfield, and Nelson (2002) recommend matching participants

\footnotetext{
${ }^{3}$ Using all 301 participants in our primary tests does not alter the statistical conclusions regarding Hypothesis 1, but Hypothesis 2 is no longer supported. However, if we use participants' perceptions of subordinate narcissism (based on manipulation check responses) rather than the assigned manipulation condition, statistical inferences of our primary tests for both hypotheses are unchanged, with both Hypotheses 1 and 2 supported.

${ }^{4}$ We excluded forty-seven participants for misidentifying high/low subordinate narcissism. These participants did not have statistical differences in age, gender, or experience from the 254 remaining participants. They did score significantly higher on the narcissism measure $(\mathrm{M}=155.77, \mathrm{SD}=33.22)$ than those retained $(\mathrm{M}=142.39, \mathrm{SD}=$ 26.49), $t(299)=3.047, p=0.003$. Performance on two attention check questions suggests misidentification was caused by inattentiveness, rather than misinterpretation of the subordinate description. The first question asked participants how the inventory write-down will impact current year profit, the second asked them to recall why the product line must be written down. Of the 254 (47) participants who passed (failed) the manipulation check, 82\% (68\%) answered the first question correctly, 91\% (75\%) answered the second question correctly, and 80\% (66\%) answered both questions correctly. All pass rates are statistically different at $\mathrm{p}<0.05$.
} 
to the goals of the study. We are investigating how mid-level managers make reporting decisions; as such, we feel our sample is an adequate proxy.

\section{Procedure}

Participants first completed screening questions to verify their education. Next, they completed the 33-item Grandiose Narcissism Scale (GNS) from Foster et al. (2015). We chose this scale over the more well-known NPI (Raskin and Terry 1988) because of inconsistencies in the factor structure of the NPI, as well as criticisms of its forced-choice format (Miller et al. 2017). The GNS reproduces the original NPI seven-factor structure (i.e., authority, selfsufficiency, superiority, vanity, exhibitionism, entitlement, and exploitativeness), and can be used as an overall measure of narcissism. After the GNS, standard demographic information was recorded (including age, gender, and managerial experience).

Participants then read a scenario where they assumed the role of a division manager tasked with reviewing a proposed inventory write-down and deciding on the final amount of the write-down. We provided participants with a probable range for the value of the inventory $(\$ 500,000$ - \$900,000) and a “most likely” value of $\$ 700,000$. We also gave participants a division profit target and demonstrated how various write-down amounts would affect division profit. If the inventory was written down below $\$ 800,000$, the division would not meet the profit target, and the "most likely" inventory value resulted in missing the profit target.

GAAP requires inventory be recorded at the lower of 1) the cost of inventory or 2) the net realizable value, which is the estimated selling price less any "reasonably predictable" costs to complete and sell the inventory (ASC 330). The scenario involved slow moving inventory from a new product line that was not performing as well as expected. This created uncertainty surrounding the selling price, and how steeply the inventory would need to be discounted, which 
gave participants leeway to deviate from the "most likely" amount. We instructed participants that meeting or exceeding the profit target was an important part of their performance evaluation. However, we did not provide actual economic incentives to choose a higher inventory valuation or record a smaller write-down. Experimental compensation was unrelated to the inventory value choice.

After the scenario, we gave participants a description of their subordinate employee (that is, the assistant controller), and the subordinate's recommendation for the inventory write-down. In all cases the subordinate recommends an aggressive, high-value, inventory estimate (i.e., a small write-down), valuing the inventory at $\$ 850,000$, which allows the division to meet the earnings target. After reviewing the subordinate estimate, participants chose the amount they would approve for the estimate. Following the main experimental materials, participants answered several follow-up questions regarding their impressions of the subordinate.

\section{Independent Variables}

We manipulated the subordinate description at two levels: high and low narcissism. Prior studies manipulating narcissism employ descriptions of fictitious individuals built from characteristics frequently used to describe high or low narcissists (e.g., Hart and Adams 2014; Adams et al. 2015) or directly from narcissism measures (e.g., Wallace et al. 2015). High narcissism characteristics used by prior studies include aggressive, rude, arrogant, bossy, selfish, and flashy. Low narcissism characteristics include sensitive, gentle, timid, modest, and cooperative.

Narcissism is a multi-faceted construct, as such, we designed our manipulations using the “360 degree” approach recommended by Lipe (2018). We utilized multiple cues representing different dimensions of the construct of interest to create manipulations that are more 
representative of an individual high or low in narcissism. We based our manipulations on the seven subcomponents of the GNS: 1) authority, 2) self-sufficiency, 3) superiority, 4) vanity, 5) exhibitionism, 6) entitlement, and 7) exploitativeness.

In the high narcissism condition, the subordinate is described as a person who puts a lot of emphasis on physical appearance (high vanity), who loves compliments (high exhibitionism), who expects to get what he wants (high entitlement), who is willing to leverage situations to create an advantage (high exploitativeness), who believes he is better than others (high superiority), who enjoys being an authority (high authority), and who does not like to delegate (high self-sufficient). We also stated that co-workers describe this individual as a narcissist.

In the low narcissism condition, the subordinate is described as a person who is not hung up on physical appearance (low vanity), who does not like to show off and is embarrassed by compliments (low exhibitionism), who hopes to get what he wants (low entitlement), who is reluctant to leverage situations (low exploitativeness), who recognizes his weaknesses and others' strengths (low superiority), who is willing to cede to authority (low authority), and who is willing to delegate (low self-sufficiency). We stated that co-workers describe this individual as modest. To try to reduce divergent impressions of non-narcissistic characteristics, the high and low narcissism subordinate each had the same background information. We described each as educated, ambitious, hardworking, personable, and funny. The exact wording of these conditions can be seen in our survey, provided in the online Appendix. ${ }^{5}$

Participant narcissism is the second independent variable of interest and was measured with the GNS. We recorded participant responses to the 33 GNS items on a seven-point Likert scale $(1=$ strongly disagree, $7=$ strongly agree $)$. All GNS items are phrased such that stronger

\footnotetext{
${ }^{5}$ Please see supporting information, "Online Appendix: Subordinate Narcissism Manipulations" as an addition to the online article.
} 
agreement (higher values) indicate more narcissistic responses. The total GNS score is calculated by summing the individual items. The mean GNS score was $142.39(\mathrm{SD}=26.49, \mathrm{n}=254)$, and the scale exhibited strong reliability $(\alpha=.93)$. The mean is slightly higher than in samples reported in Foster et al. (2015). ${ }^{6}$ We believe this may be due in part to two factors. First, they sampled a more heterogeneous population of college students, whereas we focus on business professionals. Second, their samples contained a higher percentage of females $(61 \%$ and $75 \%$ in Foster et al. 2015, compared to $48 \%$ in our sample). Prior research suggests that females are less narcissistic than males (Grijalva et al. 2015b).

\section{Dependent Variables}

To investigate $\mathrm{H} 1$, we asked participants to rate their agreement with the statement, "Casey Jones (the subordinate) is a likable person”, using a seven-point Likert scale (1 - strongly disagree, 7 - strongly agree). To investigate $\mathrm{H} 2$, we analyzed participant choices for the inventory write-down. We gave participants the following prompt, "As division manager, you are responsible for approving the inventory value amount. What amount would you record as the value of the inventory?" Participants responded by selecting an amount from a drop-down list of values between $\$ 500,000$ - $\$ 900,000$, in increments of $\$ 50,000$.

\section{Results}

\section{Descriptive Statistics}

Descriptive statistics and Spearman correlations are provided in Table 1. The sample was $52 \%$ male. Of the 254 participants, 129 (125) received the low (high) subordinate narcissism

\footnotetext{
${ }^{6}$ Foster et al. $(2015)$ reported means of $114.66(\mathrm{SD}=22.32, \mathrm{n}=980)$ and $110.71(\mathrm{SD}=21.34, \mathrm{n}=262)$. However, they recorded participant responses on a six-point scale, whereas we used a seven-point scale. To facilitate comparison, we converted total scores to percentages, based on the maximum possible score for each scale. Our average score was $61.6 \%$ of the maximum, the Foster et al. (2015) averages were $57.9 \%$ and $55.6 \%$ of the maximum, respectively.
} 
manipulation. Consistent with prior literature, age has a negative correlation with participant narcissism $(G N S){ }^{7}$ The correlation between gender and narcissism is not significant but is directionally consistent with prior studies that find females to be less narcissistic.

\section{[INSERT TABLE 1]}

Since subordinate narcissism (SubNarc) was manipulated, and participants were randomly assigned to receive either a high or low narcissism subordinate description, we did not expect, or find, SubNarc to be correlated with participant narcissism (GNS). We do observe correlations consistent with our theory. Subnarc has a negative correlation with participants' inventory estimates and likeability ratings, and a positive correlation with participants' career threat perceptions. Participant inventory values have a positive correlation with ratings of subordinate likeability, but a negative correlation with perceptions of career threat.

Our main statistical tests, reported below, are robust to controlling for both age and gender. There are also no statistically significant interactions between age, or gender, and subordinate narcissism. Older and younger people responded to subordinate narcissism in the same manner, as did males and females.

\section{Hypotheses Tests}

To test H1, we analyze participant responses regarding the subordinate likability using multiple regression. We estimate the following regression equation:

$$
\text { (1) } \text { Likable }=\beta_{0}+\beta_{1} \text { SubNarc }+\beta_{2} G N S+\beta_{3} \text { SubNarc } x \text { GNS }
$$

$$
\text { [INSERT TABLE 2] }
$$

\footnotetext{
${ }^{7}$ Foster et al. (2003) utilizes a cross-sectional design, with data collected at a single point in time, to demonstrate that older people report lower narcissism scores. Due to the relatively recent development of narcissism measures, to our knowledge, there has not been a longitudinal study of narcissism to determine how individual narcissism changes over time. The observed negative relationship cannot be clearly attributed to either a) a decline in narcissism as individuals get older or b) an increase in narcissism in younger age groups (or some combination of the two).
} 
SubNarc is a dummy variable equal to $1(0)$ if the participant was given the high (low) narcissism subordinate description. GNS is the participant's narcissism as measured by their GNS score. We mean centered the GNS scores to reduce multicollinearity and improve interpretability of the model coefficients (West, Aiken, and Krull 1996). The results of the regression are reported in Table 2. We find a significant main effect for SubNarc; participants rated the narcissistic subordinate significantly less likable $\left(\beta_{1}=-2.33, \mathrm{p}<0.001\right)$. The main effect for GNS is not significant; however, we do see a significant interaction between SubNarc and $G N S\left(\beta_{3}=0.012, \mathrm{p}<0.039\right)$. The positive sign indicates that narcissistic participants rated the narcissistic subordinate as more likable, which is consistent with narcissistic tolerance theory. ${ }^{8}$

\section{[INSERT FIGURE 1]}

Figure 1 depicts estimates produced from the regression equation for both the low and high subordinate narcissism conditions. The Y-axis represents the estimated participant likability rating for the subordinate. The $\mathrm{X}$-axis varies participant narcissism for the range of GNS scores that are $+/$ - one standard deviation from the mean GNS score $(\mathrm{M}=142.39, \mathrm{SD}=26.49)$, as recommended by West et al. (1996). The regression estimates show consistently high likability ratings for the low narcissism subordinate, regardless of participant narcissism. However, likability of the high narcissism subordinate depends on participant narcissism. Narcissistic participants find the high narcissism subordinate to be more likable. These results support H1.

To test $\mathrm{H} 2$, we analyze participant choices for the inventory value. A higher inventory value results in a lower write-down, and inventory values of at least $\$ 800,000$ allow the division to meet the profit target. We estimate the following regression equation:

\footnotetext{
${ }^{8}$ We note the relatively high $\mathrm{R}^{2}$ reported in Table $2\left(\mathrm{R}^{2}=50 \%\right)$; this is attributable to the strong correlation between subordinate narcissism and likability $(\mathrm{r}=-0.692, \mathrm{p}<0.01)$.
} 


$$
\text { (2) Inventory }=\beta_{0}+\beta_{1} \text { SubNarc }+\beta_{2} \text { GNS }+\beta_{3} \text { SubNarc } x \text { GNS }
$$

[INSERT TABLE 3]

All independent variables are the same as Equation 1. The results of the regression are reported in Table 3. We find a significant main effect for SubNarc $\left(\beta_{1}=-40.710, \mathrm{p}<0.001\right)$, with participants making lower estimates when the subordinate is narcissistic. We also find a significant main effect for $G N S\left(\beta_{2}=0.660, \mathrm{p}=0.042\right)$ with narcissistic participants making higher estimates. However, we also find a significant interaction between SubNarc and GNS ( $\beta_{3}$ $=-0.923, \mathrm{p}=0.030)$. Consistent with narcissistic hypocrisy, narcissistic participants make lower estimates when the subordinate is also narcissistic.

\section{[INSERT FIGURE 2]}

Figure 2 depicts estimates produced from the regression equation for both the low and high subordinate narcissism conditions. The $\mathrm{Y}$-axis represents the estimated inventory value. The $\mathrm{X}$-axis varies the participant narcissism for the range of GNS scores that are +/- one standard deviation from the mean. Overall, the regression estimates show low narcissism participants make more conservative inventory estimates, and ones that will not allow the division to meet the profit target (i.e., below the $\$ 800,000$ threshold), regardless of subordinate narcissism. The regression results also show that subordinate narcissism has opposite effects on narcissistic participants. When subordinates exhibit low narcissism, more narcissistic participants make increasingly aggressive inventory estimates that are above the profit target threshold. However, when subordinates exhibit high narcissism, more narcissistic participants make increasingly conservative inventory estimates. These results support $\mathrm{H} 2$.

\section{Supplemental tests}

Sensitivity tests 
We consider two alternative analyses for our primary regression analyses. First, we apply a median split of GNS scores in a 2x2 ANOVA in place of the continuous measure used in the regression analyses. We note that our results for both Hypothesis 1 and Hypothesis 2 (untabulated) are robust. Second, an alternative way to analyze inventory value choices is to categorize the values into those that allow the division to meet or beat the earnings target and those that do not. We conduct an additional test, using logistic regression. We re-code participant inventory values equal to one if they chose a value $\geq \$ 800,000$ (that is, the minimum inventory value that would still allow the division to meet the earnings target), and zero, otherwise. We find results consistent with $\mathrm{H} 2$ (untabulated), with the coefficient on SubNarc significantly negative $\left(\beta_{1}=-0.927, \mathrm{p}<0.001\right)$, the coefficient on GNS significantly positive $\left(\beta_{2}=0.018, \mathrm{p}=\right.$ $0.040)$, and the $\operatorname{SubNarc} * G N S$ interaction marginally significant, and negative $\left(\beta_{3}=-0.018, \mathrm{p}=\right.$ 0.092).

\section{Alternative Explanations}

Narcissists have been shown to exhibit greater risk-taking behavior (Campbell, Goodie, and Foster 2004). This behavior stems from their inflated beliefs about themselves (i.e., overconfidence) and their desire to prove their superiority. Supervisors might discount an aggressive estimate from a narcissistic subordinate to guard against this risk-taking proclivity. Indeed, our results show that supervisors, on average, made larger downward (i.e., conservative) adjustments when the subordinate was narcissistic. However, the risk explanation does not account for the interaction between subordinate and supervisor narcissism. Since narcissists are more accepting of risks, narcissistic supervisors should be more willing to permit an aggressive estimate. We observe this only when subordinate narcissism is low. When subordinate narcissism is high, narcissistic supervisors make more conservative inventory estimates. 
Another alternative explanation for our results is that narcissists are perceived to be less competent employees, which would provide supervisors a reason to alter their work. However, Judge et al. (2006) found that subordinate narcissism did not influence supervisor ratings of employee job performance. Also, as we will discuss below, the high narcissism subordinate was viewed as more of a career threat than the low narcissism subordinate, which suggests that the high narcissism subordinate was perceived to be at least as competent as the low narcissism subordinate. For these reasons, we believe it is unlikely that our results are attributable to differences in perceived competence of the low/high narcissism subordinate.

Does perceived career threat explain narcissistic hypocrisy?

Bushman and Baumeister (1998) provide evidence that threat perception mediated the relationship between narcissism and aggressive behavior toward an ego threat. To determine if threat perception explains narcissistic supervisors' larger adjustments to the narcissistic subordinate's estimate, we asked participants to rate their agreement with this statement: "I would view Casey Jones as a threat to my career," using a seven-point Likert scale (1 - strongly disagree, 7 - strongly agree). We then tested for mediated moderation, using structural equation modeling (SEM), to assess the extent to which perceived career threat mediates the interactive effect of subordinate and supervisor narcissism on inventory estimates ${ }^{9}$.

We used Mplus (Muthén and Muthén 2017) to conduct our analysis. If perceptions of career threat are driving the main result, we should see that narcissistic supervisors are more threatened when a subordinate exhibits narcissism, which, in turn, causes the supervisor to reject the subordinate estimate. The SEM results, including a path diagram are reported in Figure 3.

\section{[INSERT FIGURE 3 HERE]}

\footnotetext{
${ }^{9}$ Alternative tests using the Baron and Kenny (1986) regression method, and the Hayes (2012) bootstrapping method yielded the same statistical conclusions.
} 
The path of interest is the path from $\operatorname{SubNarc}^{*}$ GNS $\rightarrow$ Threat $\rightarrow$ Inventory. To be consistent with narcissistic tolerance, the coefficient on the path from SubNarc* GNS to Threat should be positive, and the coefficient from Threat to Inventory should be negative. Since the model is fully saturated, fit statistics are not available. SubNarc*GNS affects Threat in the predicted manner $(\beta=0.020, \mathrm{p}=0.001)$; more narcissistic supervisors rate the narcissistic subordinate as a greater career threat. Threat is also related to Inventory, as predicted ( $\beta=$ $5.317, \mathrm{p}=0.024)$; supervisors who feel the subordinate is a greater career threat provide lower inventory values. The indirect path from SubNarc*GNS to Inventory, through Threat can be calculated by multiplying the coefficients from $\operatorname{SubNarc}{ }^{*} G N S$ to Threat and Threat to Inventory together. A Sobel test reveals the indirect path is not significantly different from zero $(\mathrm{t}=-1.198$, $\mathrm{p}=0.115$, one-tailed, untabulated). Thus, it does not appear that career threat mediates the interactive effect of supervisors and subordinate narcissism on supervisor inventory estimates ${ }^{10}$.

We speculate that mediation was not successful because the mediator measure specifically asked supervisors to assess the career threat posed by the subordinate, and this did not adequately measure ego threat. Ex-ante, we believed career threat (being surpassed by a subordinate) was likely to be a primary concern given our setting, and a reasonable proxy for ego threat. While the mediation test showed that narcissistic supervisors considered the narcissistic subordinate to be a greater career threat, the actual magnitude of the perceived career threat was minimal. In untabulated analyses, ex post, we found that participants in both the low and high narcissistic subordinate conditions rated career threat below the midpoint of four on the sevenpoint responses scale (means of 2.15 and 3.82 for the low and high narcissistic subordinate conditions, respectively). This suggests that the narcissistic subordinate was not seen as a

\footnotetext{
${ }^{10} \mathrm{We}$ also examined likeability, and a measure of perceived similarity between the supervisor and subordinate as potential mediators. We did not find evidence that either measure mediated the main result.
} 
credible career threat. In retrospect, this is plausible, because the supervisor/subordinate relationship was made apparent. Participants must have felt that there was little career threat from someone who was clearly their junior. However, this does not exclude the narcissistic subordinate from being an ego threat, it just means narcissistic supervisors did not feel threatened in that specific way.

Both the low and high narcissism subordinate were described as educated, ambitious, hardworking, personable, and funny. The high narcissism subordinate was also described (in part) as a showoff, who likes the spotlight, believes he is better than others, and is willing to leverage situations to his advantage. This description should have provoked a comparison from narcissistic supervisors, resulting in a threatened ego, and hostility toward the subordinate (Bogart et al. 2004). We believe that ego threat is the underlying cause of our observed narcissistic hypocrisy, and that the career threat measure was simply not an adequate proxy for ego threat. We recognize this as a limitation of our research in our conclusion section.

\section{Conclusion}

As a safeguard to financial reporting quality, supervisors are tasked with reviewing accounting estimates advanced by subordinates. We use an experiment to demonstrate that supervisor reviews are significantly influenced by subordinate narcissism. Our results also demonstrate that the effect of subordinate narcissism is conditional on supervisor narcissism. We provide evidence of both narcissistic tolerance and narcissistic hypocrisy. On one hand, narcissistic supervisors are more tolerant of narcissistic subordinates, rating them as more likable. On the other hand, narcissistic supervisors are less likely to agree with narcissistic subordinates' aggressive accounting choices, even when disagreeing leads to falling short of an earnings target. 
Our research makes several contributions. Wisse et al. (2015) provided initial evidence of narcissistic hypocrisy in a sample of Dutch supervisors. We demonstrate that narcissistic hypocrisy not only influences narcissists' perceptions of other narcissists, but also affects narcissists' use of information provided by other narcissists in a meaningful management decision-making setting. Our research also contributes to accounting and business research and practice. Most business organizations, including professional accounting practices, exhibit a hierarchal structure. In such organizations, managers leverage and rely on the work of subordinate professionals. We demonstrate the importance of subordinates and their personalities in the development of accounting information. Subordinate narcissism is particularly relevant because research suggest that narcissism is increasing in younger populations (Twenge et al. 2008; Young et al. 2016). While most of the prior accounting literature focuses on the personal characteristics of executives or primary decision makers, we provide evidence that subordinates, and their personalities, can exert significant influence over the financial reporting process.

We made several significant design choices which limit the conclusions that can be drawn from our work. Perhaps most importantly, we utilized written descriptions to manipulate subordinate narcissism. While this is consistent with prior work in the area, and allows for greater experimental control, and internal validity, we do sacrifice contextual richness that is present in real life. This is most notable in two ways. First, work relationships are built over time, and across many interactions. Other research on narcissism has suggested that perceptions of narcissists may change over time (e.g., Paulhus 1998). Narcissistic hypocrisy could be moderated by the nature, and/or duration of the relationship between the supervisor and subordinate. However, we note that our results are consistent with Wisse, et al. (2015), who measured narcissism in actual pairs of supervisors/subordinates, and still found evidence 
consistent with narcissistic hypocrisy. Second, personalities are multi-faceted. Narcissists are not only narcissistic. Many researchers have noted the correlation between narcissism and two other traits, Machiavellianism and psychopathy (Dahling, Whitaker, and Levy 2009; Jonason and Webster 2010; Rauthmann 2012; Rauthmann and Kolar 2013). While there is some overlap between narcissism, Machiavellianism, and psychopathy, our manipulation was not meant to create a multi-faceted personality including Machiavellianism and Psychopathy. It is possible that the relative strength of these related traits (or other traits) within a fully formed personality could alter how one is perceived by others.

Another limitation of our work is our focus on a single type of narcissism (namely, grandiose narcissism), and our use of a specific measure of grandiose narcissism (specifically, the GNS). Narcissism is a complex construct. There is evidence of significant variation, within narcissists, on several different dimensions (e.g., Dickinson and Pincus 2003; Foster and Campbell 2007; Back, et al. 2013; Kwiatkowska, et al. 2019). A host of scales exists that vary in length (e.g., 13 - 40 questions), format (e.g., force choice versus use of Likert scales), structure (yielding $2-7$ sub-factors), and theoretical underpinnings (e.g., grandiose versus vulnerable narcissism). It is possible that some forms of narcissism are more/less conducive to narcissistic hypocrisy, as different forms of narcissism may be more or less compatible with each other. It also seems likely that the amount of narcissistic hypocrisy may be exacerbated by certain variations of narcissists (such as vulnerable narcissists). We leave it to future researchers to investigate these possibilities. Additionally, we explored a specific behavior (namely, managing earnings upwards), absent any true financial or career motives for engaging in the behavior. Narcissistic hypocrisy may be heightened or attenuated when incentives such as financial rewards, job security, and or workplace recognition are present. 
A final limitation of our study is that we did not find evidence that threat perception mediates the narcissistic hypocrisy effect. As previously discussed, we believe this lack of finding is attributable to mismeasurement of the construct (i.e., career threat versus ego threat) rather than a theoretical issue. However, we cannot rule out the possibility that narcissistic hypocrisy is caused by something other than ego threat. Future researchers could help clarify this no-result by incorporating more nuanced measures of ego threat perception. 


\section{References}

Ackerman, R. A., E. A. Witt, M. B. Donnellan, K. H. Trzesniewski, R. W. Robins, and D. A. Kashy. 2011. What does the Narcissistic Personality Inventory really measure?

Assessment 18 (1):67-87.

Adams, J. M., W. Hart, and K. A. Burton. 2015. I only like the idea of you: Narcissists tolerate others' narcissistic traits but not their corresponding behaviors. Personality and Individual Differences 82:232-236.

Ahmed, A. S., and S. Duellman. 2013. Managerial overconfidence and accounting conservatism. Journal of Accounting Research 51 (1):1-30.

Baron, Reuben M, and David A Kenny. 1986. "The moderator-mediator variable distinction in social psychological research: Conceptual, strategic, and statistical considerations." Journal of personality and social psychology 51 (6):1173.

Back, M. D., A. C. Küfner, M. Dufner, T. M. Gerlach, J. F. Rauthmann, and J. J. Denissen. 2013. Narcissistic admiration and rivalry: Disentangling the bright and dark sides of narcissism. Journal of personality and social psychology 105 (6):1013.

Baumeister R., L. Smart and M. 1996. Relation of threatened egotism to violence and aggression: The dark side of high self-esteem. Psychological Review 103:5-33.

Blair, C. A., B. J. Hoffman, and K. R. Helland. 2008. Narcissism in organizations: A multisource appraisal reflects different perspectives. Human Performance 21 (3):254-276.

Bogart, L., E. Benotsch and J. Pavlovic. 2004. Feeling superior but threatened: The relation of narcissism to social comparison. Basic and Applied Social Psychology, 26(1): 35-44.

Braun, S., N. Aydin, D. Frey, and C. Peus. 2018. Leader narcissism predicts malicious envy and supervisor-targeted counterproductive work behavior: Evidence from field and experimental research. Journal of Business Ethics 151 (3):725-741.

Buffardi, L. E., and W Keith Campbell. 2008. "Narcissism and social networking web sites." Personality and social psychology bulletin 34 (10):1303-1314.

Burton, K. A., J. M. Adams, W. Hart, B. Grant, K. Richardson, and G. Tortoriello. 2017. You remind me of someone awesome: Narcissistic tolerance is driven by perceived similarity. Personality and Individual Differences 104:499-503.

Bushman, Brad J, and Roy F Baumeister. 1998. "Threatened egotism, narcissism, self-esteem, and direct and displaced aggression: Does self-love or self-hate lead to violence?" Journal of personality and social psychology 75 (1):219. 
Campbell, W Keith, Adam S Goodie, and Joshua D Foster. 2004. "Narcissism, confidence, and risk attitude." Journal of behavioral decision making 17 (4):297-311.

Corry, N., R. D. Merritt, S. Mrug, and B. Pamp. 2008. The factor structure of the Narcissistic Personality Inventory. Journal of Personality Assessment 90 (6):593-600.

Committee of Sponsoring Organizations of the Treadway Commission (COSO). 2009. Guidance on Monitoring Internal Control Systems. Durham, NC: AICPA. . 2013. Internal Control-Integrated Framework. Durham, NC: AICPA.

Dahling, J. J., Brian G Whitaker, and Paul E Levy. 2009. "The development and validation of a new Machiavellianism scale." Journal of management 35 (2):219-257.

Dickinson, K. A., and A. L. Pincus. 2003. Interpersonal analysis of grandiose and vulnerable narcissism. Journal of personality disorders 17 (3):188-207.

Foster, J. D., and W Keith Campbell. 2007. "Are there such things as "narcissists" in social psychology? A taxometric analysis of the Narcissistic Personality Inventory." Personality and Individual Differences 43 (6):1321-1332.

Foster, J. D., W. K. Campbell, and J. M. Twenge. 2003. Individual differences in narcissism: Inflated self-views across the lifespan and around the world. Journal of research in personality 37 (6):469-486.

Foster, J. D., J. L. McCain, M. F. Hibberts, A. B. Brunell, and R. B. Johnson. 2015. The grandiose narcissism scale: a global and facet-level measure of grandiose narcissism. Personality and Individual Differences 73:12-16.

Friedman, J.N.W., T. F. Oltmanns, and E. Turkheimer. 2007. "Interpersonal perception and personality disorders: Utilization of a thin slice approach." Journal of Research in Personality 41 (3):667-688.

Grijalva, E., P. D. Harms, D. A. Newman, B. H. Gaddis, and R. C. Fraley. 2015a. Narcissism and leadership: A meta-analytic review of linear and nonlinear relationships. Personnel Psychology 68 (1):1-47.

Grijalva, E., D. A. Newman, L. Tay, M. B. Donnellan, P. D. Harms, R. W. Robins, and T. Yan. 2015b. "Gender differences in narcissism: A meta-analytic review." Psychological bulletin 141 (2):261.

Ham, C., M. Lang, N. Seybert, and S. Wang. 2017. CFO narcissism and financial reporting quality. Journal of Accounting Research.

Hampton, C. 2015. "Estimating and reporting structural equation models with behavioral accounting data." Behavioral research in accounting 27 (2):1-34.

This article is protected by copyright. All rights reserved. 
Hart, W., and J. M. Adams. 2014. Are narcissists more accepting of others' narcissistic traits? Personality and Individual Differences 64:163-167.

Hayes, Andrew F. 2013. Introduction to mediation, moderation, and conditional process analysis: A regression-based approach: Guilford Press.

Jia, Y., L. V. Lent, and Y. Zeng. 2014. Masculinity, testosterone, and financial misreporting. Journal of Accounting Research 52 (5):1195-1246.

Johnson, E. N., J. R. Kuhn Jr, B. A. Apostolou, and J. M. Hassell. 2012. Auditor perceptions of client narcissism as a fraud attitude risk factor. Auditing: A Journal of Practice \& Theory 32 (1):203-219.

Johnson, E. N., L. A. Kidwell, D. J. Lowe, and P. M. J. Reckers. 2019. "Who Follows the Unethical Leader? The Association Between Followers' Personal Characteristics and Intentions to Comply in Committing Organizational Fraud." Journal of Business Ethics 154 (1):181-193.

Jonason, P. K., and G. D. Webster. 2010. "The dirty dozen: a concise measure of the dark triad." Psychological assessment 22 (2):420.

Jones, D. N., and D. L. Paulhus. 2010. Different provocations trigger aggression in narcissists and psychopaths. Social Psychological and Personality Science 1 (1):12-18.

Judd, J. S., K. J. Olsen, and J. Stekelberg. 2016. How do Auditors Respond to CEO Narcissism? Evidence from External Audit Fees. Accounting horizons.

Judge, T. A., J. A. LePine, and B. L. Rich. 2006. Loving yourself abundantly: relationship of the narcissistic personality to self-and other perceptions of workplace deviance, leadership, and task and contextual performance. Journal of Applied Psychology 91 (4):762.

Kwiatkowska, M. M., T. Jułkowski, R. Rogoza, M. Żemojtel-Piotrowska, and R. Fatfouta. 2019. "Narcissism and trust: Differential impact of agentic, antagonistic, and communal narcissism." Personality and Individual Differences 137:139-143.

Lipe, M. G. 2018. Unpacking the disclosure package: Using experiments to investigate investor reactions to narrative disclosures. Accounting, Organizations and Society.

Maccoby, M. 2000. Narcissistic leaders: The incredible pros, the inevitable cons. Harvard Business Review 78 (1):68-78.

Miller, J. D., B. J. Hoffman, E. T. Gaughan, B. Gentile, J. Maples, and W. Keith Campbell. 2011. Grandiose and vulnerable narcissism: A nomological network analysis. Journal of personality 79 (5):1013-1042.

This article is protected by copyright. All rights reserved. 
Miller, J. D., D. R. Lynam, C. S. Hyatt, and W. K. Campbell. 2017. Controversies in narcissism. Annual Review of Clinical Psychology 13:291-315.

Murphy, P. R. 2012. Attitude, Machiavellianism and the rationalization of misreporting. Accounting, Organizations and Society 37 (4):242-259.

Olsen, K. J., K. K. Dworkis, and S. M. Young. 2013. CEO narcissism and accounting: A picture of profits. Journal of Management Accounting Research 26 (2):243-267.

Olsen, K. J., and J. Stekelberg. 2015. CEO narcissism and corporate tax sheltering. The Journal of the American Taxation Association 38 (1):1-22.

Paulhus, D. L. 1998. "Interpersonal and intrapsychic adaptiveness of trait self-enhancement: A mixed blessing?" Journal of personality and social psychology 74 (5):1197.

Paulhus, D. L. 2014. Toward a taxonomy of dark personalities. Current Directions in Psychological Science 23 (6):421-426.

Raskin, R., and H. Terry. 1988. A principal-components analysis of the Narcissistic Personality Inventory and further evidence of its construct validity. Journal of personality and social psychology 54 (5):890.

Rauthmann, J. F. 2012. "The Dark Triad and interpersonal perception: Similarities and differences in the social consequences of narcissism, Machiavellianism, and psychopathy." Social Psychological and Personality Science 3 (4):487-496.

Rauthmann, J. F, and G. P. Kolar. 2013. "Positioning the Dark Triad in the interpersonal circumplex: The friendly-dominant narcissist, hostile-submissive Machiavellian, and hostile-dominant psychopath?" Personality and Individual Differences 54 (5):622-627.

Rosenthal, S. A., and T. L. Pittinsky. 2006. Narcissistic leadership. The Leadership Quarterly 17 (6):617-633.

Schrand, C. M., and S. L. Zechman. 2012. Executive overconfidence and the slippery slope to financial misreporting. Journal of accounting and economics 53 (1):311-329.

Twenge, J. M., and S. M. Campbell. 2008. Generational differences in psychological traits and their impact on the workplace. Journal of Managerial Psychology 23 (8):862-877.

Twenge, J. M., and J. D. Foster. 2010. Birth cohort increases in narcissistic personality traits among American college students, 1982-2009. Social Psychological and Personality Science 1 (1):99-106.

Twenge, J. M., S. Konrath, J. D. Foster, W. Keith Campbell, and B. J. Bushman. 2008. Egos inflating over time: A cross-temporal meta-analysis of the Narcissistic Personality Inventory. Journal of personality 76 (4):875-902.

This article is protected by copyright. All rights reserved. 
Wallace, H. M., A. Grotzinger, T. J. Howard, and N. Parkhill. 2015. When people evaluate others, the level of others' narcissism matters less to evaluators who are narcissistic. Social Psychological and Personality Science 6 (7):805-813.

West, S. G., L. S. Aiken, and J. L. Krull. 1996. Experimental personality designs: Analyzing categorical by continuous variable interactions. Journal of personality 64 (1):1-48.

Wisse, B., D. P. Barelds, and E. F. Rietzschel. 2015. How innovative is your employee? The role of employee and supervisor Dark Triad personality traits in supervisor perceptions of employee innovative behavior. Personality and Individual Differences 82:158-162.

Young, S. M., F. Du, K. K. Dworkis, and K. J. Olsen. 2015. It's All about All of Us: The Rise of Narcissism and Its Implications for Management Control System Research. Journal of Management Accounting Research 28 (1):39-55.

Vazire, S., L. P. Naumann, P. J. Rentfrow, and S. D. Gosling. 2008. "Portrait of a narcissist: Manifestations of narcissism in physical appearance." Journal of Research in Personality 42 (6):1439-1447. 
TABLE 1

Descriptive Statistics and Spearman Correlations

\begin{tabular}{lccccccc} 
& & & & \multicolumn{3}{c}{ Inventory } & \multicolumn{2}{c}{ Career } \\
Mean & Age & Gender & SubNarc & GNS & Value & Likable & Threat \\
\cline { 2 - 8 } SD & 47.35 & 0.52 & 0.49 & 142.39 & 780.12 & 4.89 & 2.97 \\
n & 15.22 & 0.50 & 0.50 & 26.49 & 90.28 & 1.66 & 1.62 \\
& 254 & 254 & 254 & 254 & 254 & 254 & 254
\end{tabular}

Age

Gender $\quad .287 * *$

SubNarc $\quad 031-023$

GNS $-.258 * * \quad .016$

Inventory Value $\quad .023 \quad-.008 \quad-.247^{*}$

Likable $\quad-.065 \quad-.001$

$\begin{array}{lll}\text { Career Threat } \quad-.044 & .002\end{array}$

$\begin{array}{rrr}-.698 * * & .065 & \\ .524 * * & .018 & .221 * * \\ & .085 & -.202 * *\end{array}$

**Correlation significant at 0.01 level (two-tailed)

Gender was coded as 0 - female, 1 - male

Subnarc was coded as 0 - low subordinate narcissism, 1 - high subordinate narcissism GNS = participant score on the Grandiose Narcissism Scale

Inventory Value $=$ participant inventory value estimate (in thousands of dollars)

Career Threat $=$ participant rating of the subordinate as a career threat $(1-7$ scale $)$

Likability $=$ participant rating of how likable they find the subordinate $(1-7$ scale $)$

This article is protected by copyright. All rights reserved. 
TABLE 2

Subordinate Likability

\begin{tabular}{|c|c|c|c|c|}
\hline Variable & Predicted & $\underline{\beta}$ & $\underline{\text { t-stat }}$ & p-value \\
\hline Intercept & & 6.016 & 57.437 & $<0.001$ \\
\hline SubNarc & & -2.330 & -15.621 & $<0.001$ \\
\hline GNS & & $<0.001$ & 0.006 & 0.995 \\
\hline SubNarc * GNS & + & 0.012 & 2.070 & 0.039 \\
\hline $\mathrm{n}$ & & 254 & & \\
\hline $\mathrm{R}^{2}$ & & $50 \%$ & & \\
\hline
\end{tabular}

Likable $=\beta_{0}+\beta_{1} \operatorname{SubNarc}+\beta_{2}$ GNS $+\beta_{3}$ SubNarc x GNS

SubNarc $=1(0)$ if the participant was in the high (low) subordinate narcissism condition. GNS $=$ the mean-centered participant GNS score. The dependent variable, Likable = participant rating of the subordinate from the question, "Rate your agreement with the following statement: (The subordinate) is a likable person", using a 7-point scale from (1 - strongly disagree, 7 - strongly agree). All p-values are two-tailed. Variable definitions are provided in Table 1.

This article is protected by copyright. All rights reserved. 


\section{TABLE 3}

Inventory Values

\begin{tabular}{lcrrr} 
Variable & Predicted & \multicolumn{1}{c}{} & $\underline{\text { t-stat }}$ & p-value \\
\cline { 2 - 4 } & & 801.474 & 103.073 & $<0.001$ \\
SubNarc & & -40.710 & -3.676 & $<0.001$ \\
GNS & 0.660 & 2.047 & 0.042 \\
SubNarc *GNS & - & -0.923 & -2.177 & 0.030 \\
& & & \\
$\mathrm{n}$ & 254 & & \\
$\mathrm{R}^{2}$ & $7 \%$ & & \\
& \\
Inventory $=\beta_{0}+\beta_{1}$ SubNarc $+\beta_{2}$ GNS $+\beta_{3}$ SubNarc X GNS
\end{tabular}

SubNarc $=1(0)$ if the participant was in the high (low) subordinate narcissism condition. GNS = the mean-centered participant GNS score. The dependent variable, Inventory $=$ participant choice of inventory value. An inventory value of at least $\$ 800 \mathrm{~K}$ was needed to meet the division profit target. All p-values are two-tailed. Variable definitions are provided in Table 1.

This article is protected by copyright. All rights reserved. 
Figure 1 Plot of Likability Regression Estimates

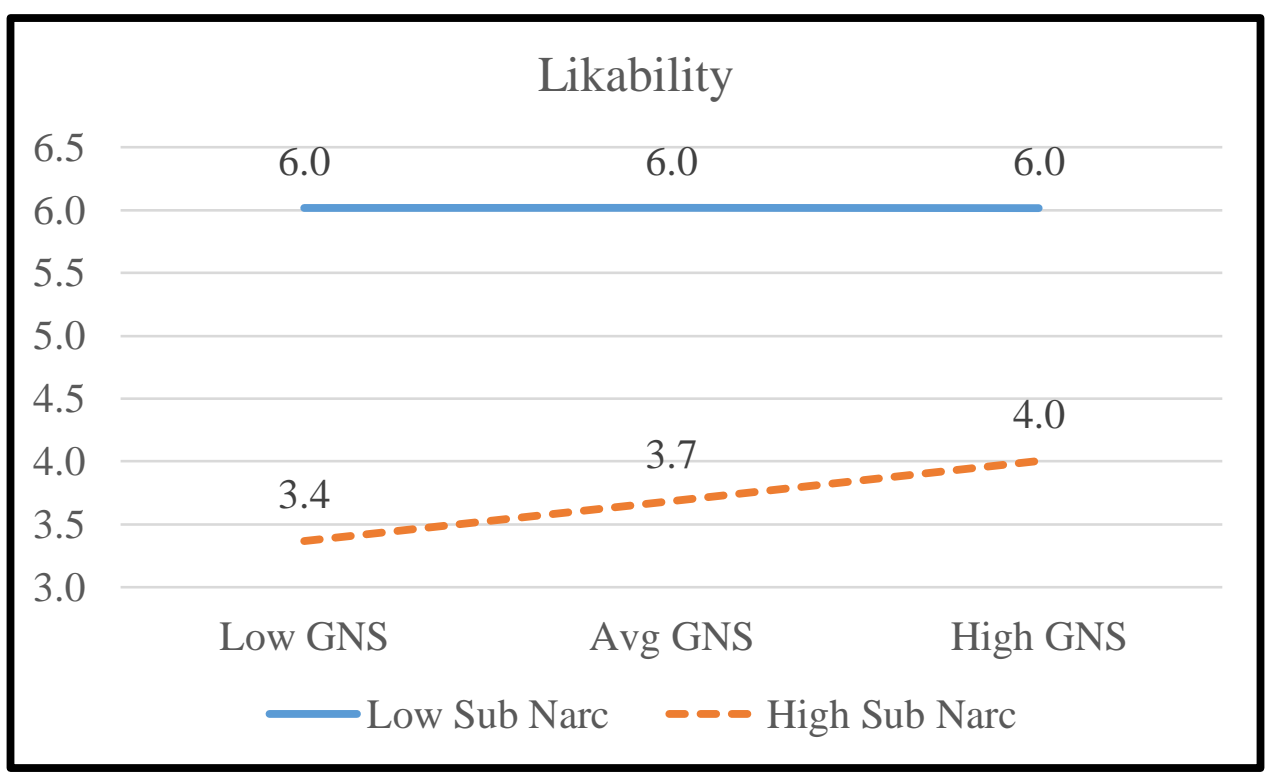

Figure 1 shows predicted mean ratings of subordinate likability based on the regression described in Table 2. Low/High GNS are at $-1 /+1$ standard deviation from the mean GNS score. Variable definitions are provided in Table 1.

This article is protected by copyright. All rights reserved. 
Figure 2 Plot of Inventory Value Regression Estimates

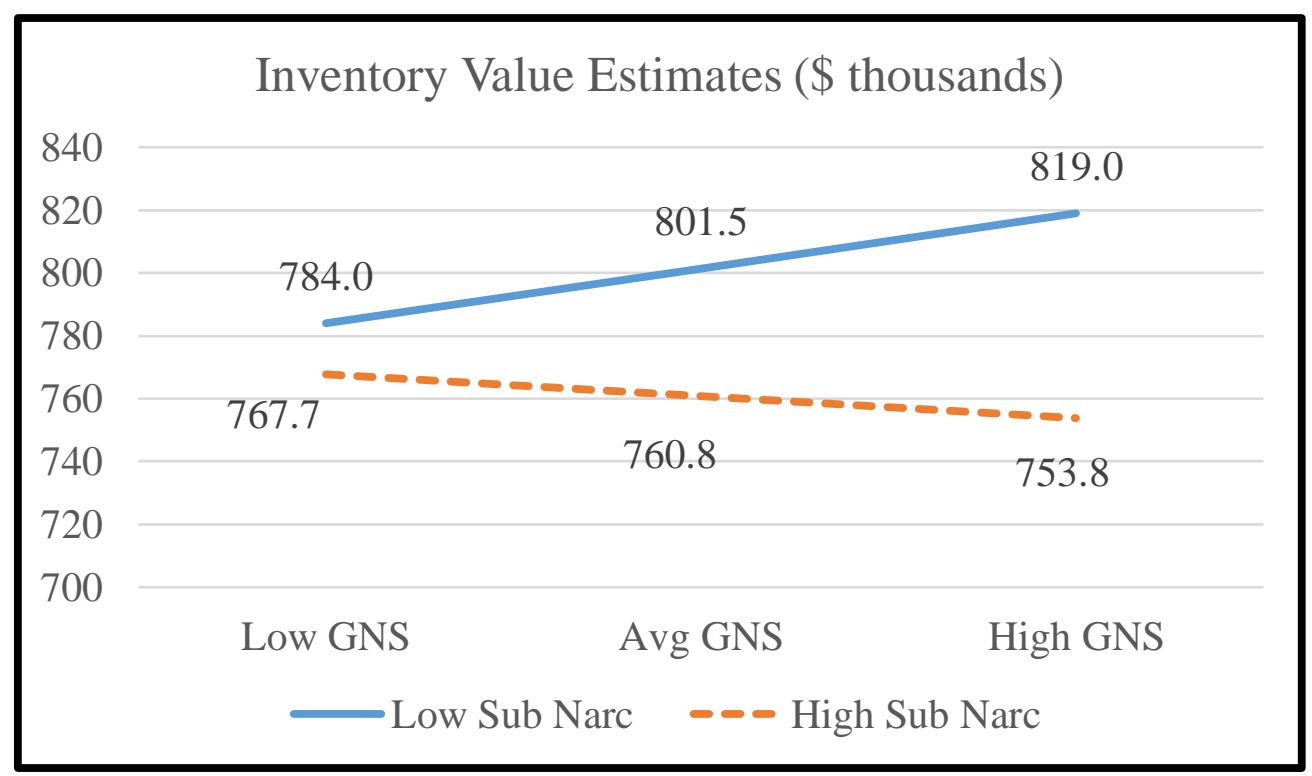

Figure 2 shows predicted mean inventory values based on the regression described in Table 3. Low/High GNS are at -1/+1 standard deviation from the mean GNS score. Variable definitions are provided in Table 1.

This article is protected by copyright. All rights reserved. 
Figure 3 SEM Model 1 (ML Estimation)

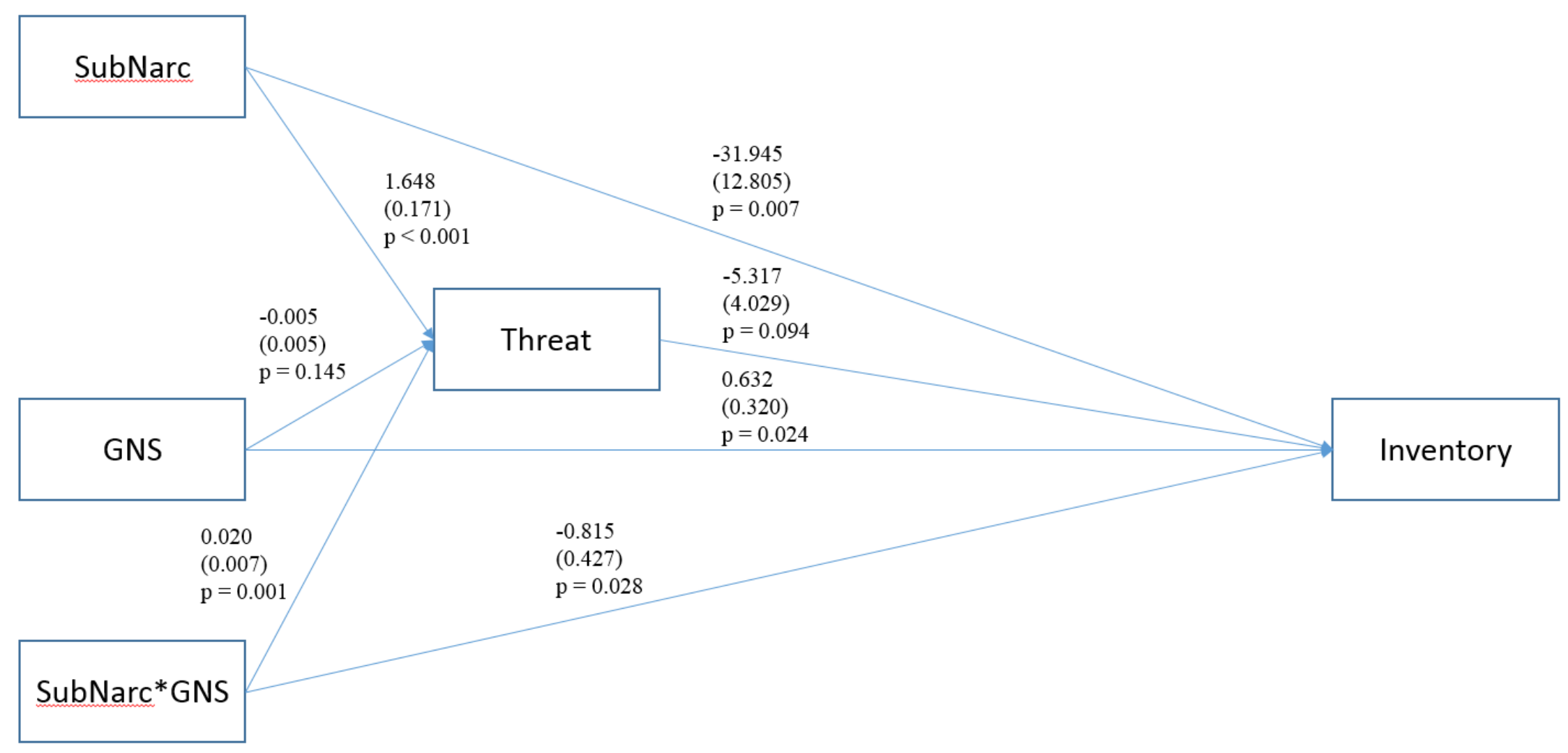

$\mathrm{N}=254$

Fit indices - not available for fully saturated models.

Threat $\mathrm{R}^{2}=0.305$, Inventory $\mathrm{R}^{2}=0.074$

SubNarc $=0$ (1) for low (high) subordinate narcissism

GNS = mean centered participant GNS score

Threat $=$ Participant response to "I would view [the subordinate] as a threat to my career" (1 - 7 scale $)$

Inventory $=$ Participant inventory dollar value recommendation

Next to each path is, from top to bottom: path coefficient, standard error, and p-value (one-tailed).

This article is protected by copyright. All rights reserved. 